Portland State University

PDXScholar

Summer 7-26-2018

\title{
Grammatical Errors by Arabic ESL Students: an Investigation of L1 Transfer through Error Analysis
}

\author{
Aisha Saud Alasfour \\ Portland State University
}

Follow this and additional works at: https://pdxscholar.library.pdx.edu/open_access_etds

Part of the Applied Linguistics Commons, and the First and Second Language Acquisition Commons Let us know how access to this document benefits you.

\section{Recommended Citation}

Alasfour, Aisha Saud, "Grammatical Errors by Arabic ESL Students: an Investigation of L1 Transfer through Error Analysis" (2018). Dissertations and Theses. Paper 4551.

https://doi.org/10.15760/etd. 6436

This Thesis is brought to you for free and open access. It has been accepted for inclusion in Dissertations and Theses by an authorized administrator of PDXScholar. Please contact us if we can make this document more accessible: pdxscholar@pdx.edu. 
Grammatical Errors by Arabic ESL Students:

An Investigation of L1 Transfer through Error Analysis

by

Aisha Saud Alasfour

A thesis submitted in partial fulfillment of the requirements for the degree of

Master of Arts
in
Teaching English for Speakers of Other Languages

Thesis Committee:

Susan Conrad, Chair

Alissa Hartig

Linnea Spitzer

Portland State University

2018 
(C) 2018 Aisha Saud Alasfour 


\begin{abstract}
This study investigated the effect of first language (L1) transfer on Arabic ESL learners' acquisition of the relative clauses, the passive voice and the definite article. I used Contrastive Analysis (CA) and Error Analysis (EA) to analyze 50 papers written by Arabic ESL students at the ACTFL Advanced Mid proficiency level. The analysis was paired with interviews with five advanced students to help determine whether L1 transfer was, in fact, influencing students' errors predicted by CA.

Students in this study made L1 errors along with other errors. Although no statistical difference was found between the frequency of transfer and other (non-transfer) errors, L1 transfer errors were still common for many learners in this data. The frequency of the relative clause L1 transfer errors was slightly higher than other errors. However, passive voice L1 errors were as frequent as other errors whereas definite article L1 errors were slightly less frequent than other errors.

The analysis of the interviews suggested that L1 still played a crucial role in influencing learners' errors. The analysis also suggested that the frequency of transfer errors in the papers used in this study might have been influenced by CA-informed instruction students received and students' language level. Specifically, learners reported that both factors helped them reduce the frequency of L1 transfer errors in their writing.

The teaching implications of this study include familiarizing language instructors with possible sources of errors for Arabic ESL learners. Language instructors should try to identify sources of errors by conducting their own analyses or consulting existing
\end{abstract}


literature on CA paired with EA. Finally, I recommend adopting a CA-informed instruction to help students reduce and overcome errors that are influenced by their L1. 


\section{Acknowledgments}

First, I give all my praise to his Almighty, Allah for granting me strength and determination to achieve my dreams in perusing my higher education and becoming a language educator.

I also want to express my gratitude for my rock, my friend and my soulmate, my husband Mohammad for his love and support. I would like to thank my dear parents for teaching me the value of family, integrity and sharing. I would also like to thank my lovely children for their unconditional love, my sweet and caring brothers for always having my back, my aunt Haya for being my mentor, my lovely cousin Muneera and my friend Shayma for their constant love and support.

I would also express my appreciation for my brilliant thesis advisor, Dr, Susan Conrad for being such a responsive, supportive and understanding teacher.

I would also like to thank my committee members Dr. Alissa Hartig and Linnea Spitzer for their thoughtful insight and feedback.

Finally, I would like to thank coordinators and senior instructors at Portland State University’s Intensive English Language Program (IELP) and especially Naoko Horikawa, Kellie Gallagher, Brett Bolstad and Della Jean Abraham for their help and cooperation.

Without the support of Allah along with you all, I would not have been able to write this thesis. Thank you. 
Table of Contents

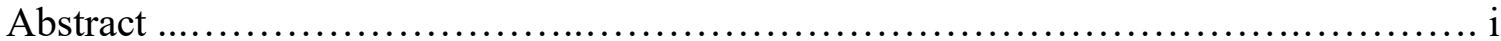

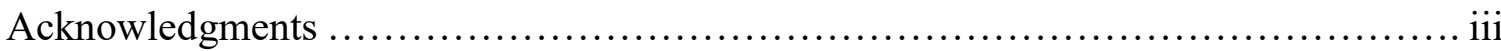

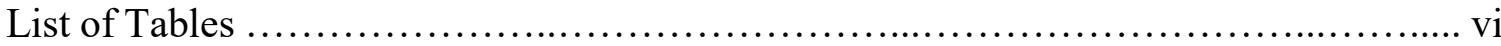

CHAPTER 1: INTRODUCTION.................................................... 1

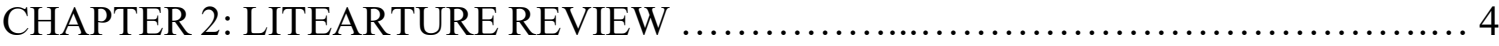

2.1. The Importance of Grammar .................................... 4

2.2. Contrastive Analysis and Error Analysis ............................ 5

2.3. Studies of Arabic L1 Transfer ....................................... 10

2.3.1. Relative Clauses ............................................... 12

2.3.2. Passive Voice .................................................. 18

2.3.3. Definite Article ................................................ 21

2.4. Interviews and L1 Transfer ........................................ 23

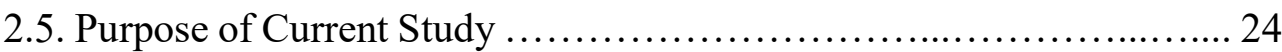

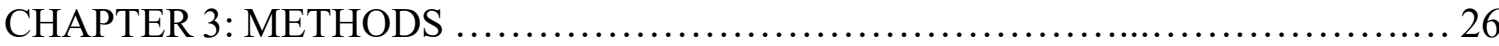

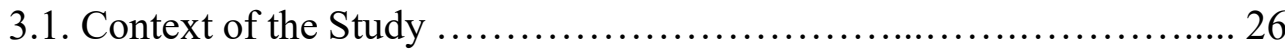

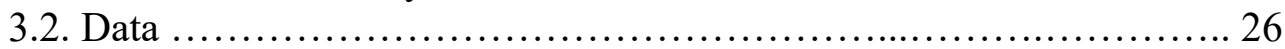

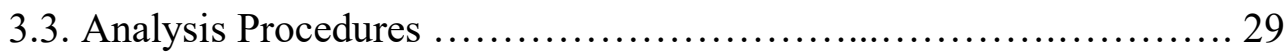

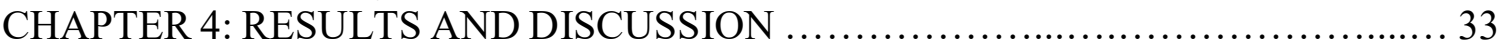

4.1. Relative Clause Errors ............................................... 33

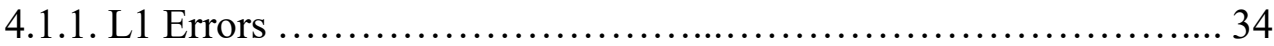

4.1.2. Non-L1 Errors .................................................. 36

4.1.3. Comparison between High and Low-Achieving Students .............. 38

4.1.4. Statistical Analysis, Summary and Findings ............................ 39

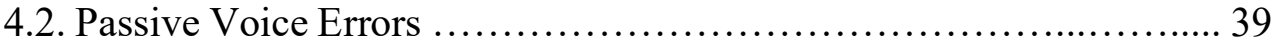

4.2.1. L1 Errors ............................................................. 40

4.2.2. Non-L1 Errors .................................................... 41

4.2.3. Comparison between High and Low-Achieving Students ...............43

4.2.4. Statistical Analysis, Summary and Findings .......................... 44

4.3. Definite Article Errors .............................................. 45

4.3.1. L1 Errors ............................................................... 45

4.3.2. Non-L1 Errors ....................................................... 46

4.3.3. Comparison between High and Low-Achieving Students ............ 47

4.3.4. Statistical Analysis, Summary and Findings ........................ 48

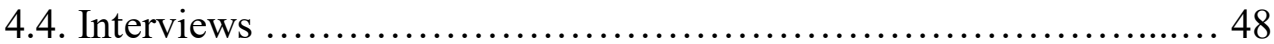

4.4.1. Students' Transfer Habits ............................................... 49

4.4.2. Effect of Instruction .................................................... 51

4.4.3. Effect of Students' Level ........................................... 54

4.5. Summary of Written Data and Interviews ............................ 56

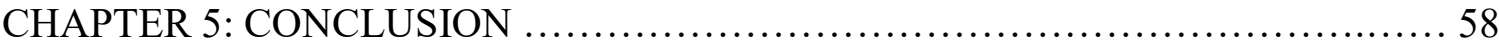

5.1. Research Questions and Summary of Findings ....................... 58

5.2. Pedagogical Implications and Applications ............................... 61

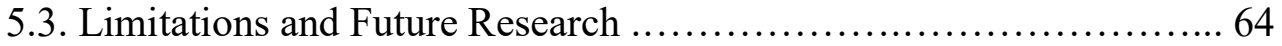

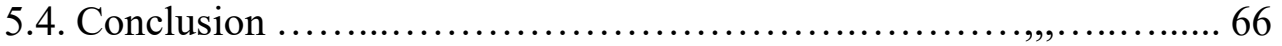




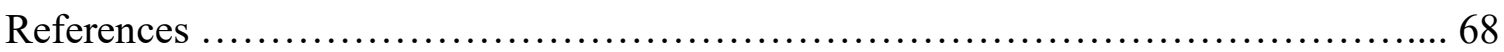

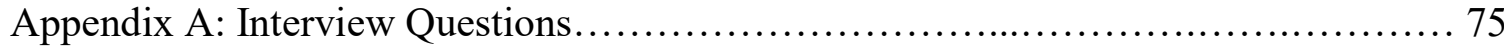

Appendix B: IRB Approval .................................................... 77 


\section{List of Tables}

Table

Page

4.1. Categories and raw frequencies of relative clause L1 errors $\ldots \ldots \ldots \ldots \ldots \ldots \ldots \ldots \ldots$

4.2. Categories and raw frequencies of relative clause non-L1 errors ................ 36

4.3. Relative clause error distribution among papers receiving $80 \%$ and above

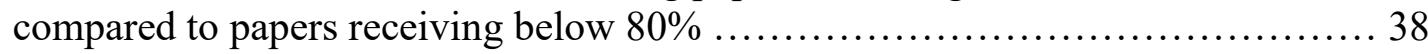

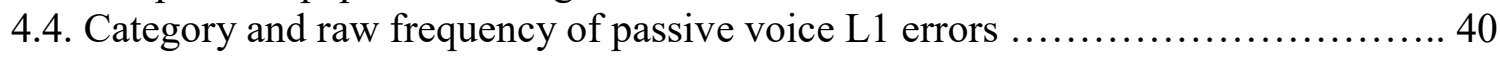

4.5. Category and raw frequency of passive voice non-L1 errors ................... 41

4.6. Passive voice error distribution among papers receiving $80 \%$ and above compared

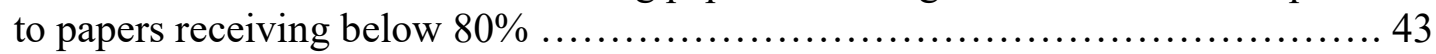

4.7. Category and raw frequency of the definite article L1 errors .................... 46

4.8. Categories and raw frequencies of the definite article non-L1 errors ............. 46

4.9. Definite article error distribution among papers receiving $80 \%$ and above compared

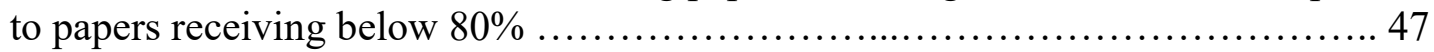




\section{Chapter 1}

\section{Introduction}

"Think in English!” That was how I used to end any discussion with my brothers, my friends and husband on how bizarre English grammar was to them. My judgment was entirely based on my personal experience with English, that mysterious extra-terrestrial creature that I fell in love with. I am not sure whether it was my instincts or if I was advised by a former English teacher to treat English as a different entity than my first language, Arabic, and not to think in Arabic while communicating in English. Throughout my years of learning English, I kept reminding myself not to think in Arabic because every time I did, I came up with either grammar errors or sentences that were literal translations of Arabic. It was not until I joined the Master of Arts program in Teaching English for Speakers of Other Languages (MA TESOL) program at Portland State University (PSU) that I learned explicitly about the effect of negative transfer on language learning. Negative transfer is defined as "learner difficulty and error" caused by varying "comparable" constructions between two languages (VanPatten \& Williams, 2015, p. 20). For example, the absence of the indefinite article in Arabic might influence Arabic learners of English to drop the indefinite article and produce sentences like the following:

*Noel is reading book.

*Sam bought blouse.

I came across similar examples when I did a pilot study examining grammatical errors made by Arab students enrolled in PSU first-year classes. Those examples clearly 
corresponded to negative transfer, suggesting the students' reliance on their first language (L1) led them to produce ungrammatical sentences in their second language (L2). The same applied to ESL students around me who had a hard time understanding how some grammatical features worked because they were using their knowledge about Arabic to produce English constructions, consciously or subconsciously. I knew that they were not "thinking in English" but I did not have the tools to explain the how and the why.

When I examined the literature on Arabic students' acquisition of grammatical features, three features stood out as commonly studied and also occurring in the sample which I studied in my pilot study: the definite article, relative clause and passive voice. I also found that most of the literature on these features discussed students' errors in an English as Foreign Language context (EFL) (e.g., Scott \& Tucker, 1974; Kharma 1981; Alhaysony 2012; Alotaibi \& Alajmi, 2015). I was interested in researching the English as Second Language (ESL) context to see whether the same features were problematic to Arabic ESL students and whether L1 transfer accounted for the difficulty learners faced. Moreover, the research that dealt with the ESL context is dated and has not been updated in decades (e.g. Schachter, 1974; Nasser, 1983; Touchie, 1983). Since language exposure is one of the main characteristics that differentiates the ESL from the EFL context, I wanted to examine whether more language exposure might have an effect of L1 transfer on Arabic ESL learners' error production.

In addition, results from quantitative studies had me wondering about what happens in learners' minds when they make errors related to the grammatical features in question. While a few studies sought to investigate the effect of L1 transfer by having learners report on their experiences with L1 transfer and their attitudes towards it 
(Touchie, 1983; Aronin \& Toubkin 2002; Lui, 2013), only the study conducted by Touchie (1983) focused on Arabic ESL learners of English.

My previous experiences learning and teaching English inspired me to design this thesis to examine errors made by Arab students studying English as a Second Language (ESL) and investigate whether the errors were, in fact, inspired by L1 transfer. I focused on the grammatical features mentioned earlier - the definite article, relative clauses and passive voice. To achieve this, I analyzed errors made by Arabic ESL learners of English in a U.S. institution who are at an ACTFL Advanced Mid level of proficiency. The analysis was followed by interviews with ESL students attending the same institution to get more insight into the role of L1 transfer in students' acquisition of the features in question. The findings may be helpful to ESL teachers in identifying causes of errors to help their students understand the role their L1 plays in the acquisition of these problematic features.

In the next chapter I survey previous literature and the differences between Arabic and English grammar in relation to the features I investigated. I also discuss the purpose of my study. In Chapter 3, I describe the context of my study, the data and the analysis methods. I discuss my results and findings after examining two sets of data in Chapter 4 . Finally, in Chapter 5, I provide a summary of the goals of my study, the results and findings. I also address the limitations and implications of my study as well as suggestions for future research. 


\section{Chapter 2}

\section{Literature Review}

Grammar is one of the most important components of any language. In this chapter, I highlight the importance of grammar for language learners and shed light on two major analyses adopted by applied linguists to analyze learner errors, namely contrastive analysis (CA) and Error Analysis (EA). I describe differences between my participants' mother tongue, Arabic, and the grammar of English, and provide an overview of studies of Arabic L1 transfer related to the grammatical features that I studied. I review the literature on the use of interviews as a useful tool to investigate L1 transfer. In the final section of this chapter I discuss the purpose of my study along with the questions guiding my research.

\subsection{The Importance of Grammar}

English is the lingua franca of trade, science, politics, entertainment, medicine, and technology. Therefore, the demand for English learning is increasing worldwide. Because learning a language entails learning its grammar, scholars such as Ur (2006) stress the fact that "a knowledge - implicit or explicit - of grammatical rules is essential for the mastery of a language" (p. 4). In order to achieve communicative competence, which is the goal of language acquisition, language learners have to have grammar knowledge in addition to other skills (NCLRC, 2017; Zhang, 2009). Grammar is one important tool language learners need for successful interaction with other language users. 
Individuals with poor grammar may be deprived from filling certain social positions. Lack of proficiency due to inadequate grammar knowledge might affect the person's credibility in some contexts. Praise and Meenakshi (2014) pointed to the "control" or the power proper grammar has in everyday life: "glaring errors in spellings and punctuation are judged before the content of the work" (p. 101). In order to examine grammatical errors that language learners make, researchers have used various analytical approaches. The next section will cover two of the major analyses used to investigate language learners' grammatical errors.

\subsection{Contrastive Analysis and Error Analysis}

This section provides an overview of two of the analyses that have influenced the grammar analysis in my study. I believe that these two approaches are inseparable when examining the L1 transfer effect in learners' data because they complement each other.

Decades ago, linguists such as Henry Sweet and Harold Palmer, among others, suspected that the learner's first language has an effect on the acquisition of the second language. In his book The Principles of Language, Palmer (1949) discussed the case of Belgian refugee children who came to England and learned English as a second language. He said that most of the younger children learnt English and there was no interference whatsoever from their mother tongue. However, older children - whose age he did not specify -made mistakes that were clearly due to interference from their first language. $\mathrm{He}$ accounted for differences experienced by both groups of children by saying that older children had a good command of their L1. Older children also possessed a greater analytical capacity which facilitated their applying the rules of their L1 to their L2: 
$\mathrm{He}$ - an older Belgium child - was older enough and clever enough to receive eye-impressions side by side with ear impressions. He was old enough to pay attention, he was intelligent enough to concentrate, he was skillful enough to analyse and compare the second language with his first, he was able to translate. These things had a harmful influence on his work; they interfered with the processes by which nature causes us to assimilate and to remember, and the quality of his English suffered; it was a certain extent 'foreigner's' English, whereas his younger brothers spoke ‘English' English” (p.41)

This belief was soon influenced by the behaviorist theory of learning, which was based on the belief that language learning, just like any other behavior, was acquired through repetitions aimed at overcoming the effect of learners' L1 and achieving L2 competence (VanPatten \& Williams, 2015, p.20).

From these roots Charles Fries established contrastive analysis (CA) in the mid1940s amid waves of support and opposition. Fries believed that in order for language teaching materials to be effective, they needed to include explicit descriptions of the differences and similarities between the learners' first language and the language to be learnt (Khansir \& Tabande, 2014, p. 64). CA attracted the "most spirited controversies" in the field of foreign language teaching, and Robert Lado was one of its strongest advocates (Sridhar, 1975, p. 3). Lado's book Linguistics Across Cultures demonstrated the contrastive analyses of vocabulary, grammar structures and sound systems of various languages. His analyses contained detailed comparisons between learners' L1s and L2 and predicted areas of potential difficulties learners might face based on those 
comparisons (Myles, 2010). Lado's book inspired scholars to design teaching materials based on CA and led to the birth of the Michigan Test of English Language Proficiency (Kramsch, 2007).

CA's association with Skinner's behaviorist theory, however, led to skepticism about it, especially after Chomsky's (1959) criticism of verbal behaviorism. Chomsky showed that children produce novel language constructions that they had never heard before. Therefore, he claimed, children are born with an innate ability, which he called Universal Grammar (UG), which enables them to learn language. His theory placed behaviorism and CA under heavy fire.

In the 1960s, Corder (1967) challenged behaviorism and CA by saying that most of learners' errors were instances of their interlanguage. That is, he argued, errors resulted from learners' attempts to test hypotheses about the new language. Corder's hypothesis that learners' errors were not caused by the "persistence of old habits" (Corder, 1967, p.168) caused a major shift from CA to error analysis (EA) (Myles, 2010).

The stronger version of CA which was said to predict learners' errors and identify areas of difficulty for learners by the mere comparison of two languages without examining learner data was replaced by a softer one. CA was "assigned an exploratory role" (Sajaavara, 2000, p. 208). The use of CA was coupled with EA, so learners' data was first analyzed through EA. Once errors were analyzed, CA helped researchers pinpoint errors that were likely caused by learners' negative transfer of their L1 knowledge. The analysis of learners' errors through EA, on the other hand, made it clear to researchers that $\mathrm{L} 1$ transfer accounted for some, but not all, the difficulty faced by language learners (Kramsch, 2007). 
Dulay and Burt (1973) carried out two studies inspired by the UG and EA to provide empirical evidence for interlanguage errors. They conducted two studies on L1 Spanish children learning English a second language and found that only three percent of their errors could be traced back to their L1 while the remaining errors were developmental, i.e. interlanguage errors. Dulay and Burt replicated their study in 1982 recruiting a larger number of participants from varied L1 backgrounds (cited in Myles, 2010). Results showed a minimal effect of children's L1s on their L2 acquisition and that children of different L1s acquired 13 grammatical features in the same way. From that point on, CA fell out of favor due its "lack of a solid predictive theory" (Berzak, Reichart \& Katz, 2016, p. 2).

Nonetheless, many linguists were convinced that L1 was, in fact, influencing some of the errors made by language learners. Cook (1991) argued that learners' L1 and L2 influenced one another and that the brain of a bilingual is not divided into two separate monolingual minds; no empirical research was conducted by the researcher to prove his point, however. Meanwhile, questions about UG remained unanswered such as the nature of learners' initial state, i.e. the grammar that exists in the mind of learners at the beginning of their L2 acquisition. Scholars such as Schwartz and Sprouse (1996) argued that learners would start out transferring all the parameters from their L1 and would adjust the parameters based on their observation of positive evidence they received from the L2 input. Their findings incorporated both UG and the weaker version of CA. In the same vein, Herschensohn (cited in Myles, 2010) argued that learners utilized a collection of resources including L1 and UG to formulate second language grammar and vocabulary. 
By 2000, CA and EA were often combined in studies, a research tradition that will be continued in my study. Sajaavara (2000) noted that "contrastive analysis remains a useful tool in the search for potential sources of trouble in foreign language learning" (p.208). The use of CA enables researchers to explore differences between the learners' errors that are influenced by their $\mathrm{L} 1$ and interlingual errors.

The millennium witnessed the continuation of the use of CA for many pedagogical purposes such as the use of CA-informed instruction accompanied by translation in the study conducted by Laufer and Nany (2008) to teach single words and collocations. The researchers found that among the three groups that received vocabulary instruction the group that received CA-informed instruction outperformed the groups that received meaning focused instruction (MFI) and non-contrastive form-focused instruction (FFI).

The use of CA increased in the 2000s especially with the availability of learner corpora, which granted researchers and language instructors access to larger bodies of data. Therefore, CA paired with EA were used in analyzing learner data in studies such as Hong et al (2011). The researchers used the English of Malaysian School Students to examine sources of errors in using English collocations. Another example is Paquot (2017) study which used the International corpus of learner English (ICLE) to analyze the use of English lexical bundles by French and Spanish L1 EFL learners.

As for the methodology of using CA, Serdhar (1976) discussed the principles of conducting it. He emphasized that researchers seeking to compare two languages through CA have to ensure that they can access "accurate" and "explicit" descriptions of the languages they are to investigate. The second principle is having compatible descriptions 
of the languages that are being analyzed. As for the focus of the comparison, it can be either on whole systems or subsystems, i.e. a researcher can analyze a certain closed class such as the definite article or focus on one of the articles, e.g. the definite article. As I mentioned earlier, while the stronger version of CA was predictive in nature as it sought to predict learner errors based on the similarities or differences between languages, the softer version of CA is exploratory and is usually paired with EA. The latter helped explained sources of errors rather than hypothesizing about errors.

By using CA in analyzing learners' errors, I am hoping to provide more insights into the source of difficulty encountered by Arabic ESL learners and help teachers understand why learners of that L1 background find the investigated areas problematic.

\subsection{Studies of Arabic L1 Transfer}

There are many differences between Modern Standard Arabic (MSA), which Arabic learners acquire through formal education as opposed to the dialectal varieties that vary from (MSA), and English. These differences might cause learner difficulty. Previous literature highlighted the differences between Arabic and English phonology, orthography and punctuation, and grammar in general (e.g., Smith, 2001). Other studies focused on differences in one linguistic branch such as syntax (e.g.Noor, 1996) while others focus on specific grammatical features such as relatives (e.g., Washali \& Hasnain, 2013). In this section, I focus on the differences between three grammatical features that vary from MSA to English and cause learner difficulty: relative clauses, passive voice and the definite article. 
These three features have been documented in previous literature as problematic for Arabic learners of English. Most studies that dealt with the effect of Arabic L1 transfer on learners' use of these grammatical features were conducted in an English as a Foreign Language (EFL) context, e.g. Scott and Tucker (1974), Kharma (1981), Alhaysony 2012, and Alotaibi and Alajmi (2015) and Shalaby (2014). English as a Second Language (ESL) contexts have not received adequate attention. In addition, the majority of the studies that exist are dated, e.g. Schachter (1974), Nasser (1983) and Touchie (1983). Other studies that dealt with Arabic L1 transfer did not make a clear distinction between the EFL and the ESL contexts and use them interchangeably. Confusion over the two contexts was evident in articles written by Shalaby (2014) and Crompton (2011), who listed an EFL study by Bataineh (2005) as being an ESL study.

Due to the lack of transfer research in the ESL setting and the scarcity of current ESL studies, we don't know if Arabic students in an ESL setting exhibit transfer effects. There are many differences between the ESL and the EFL settings. The distinction between ESL and EFL is, however, based mainly on whether English is being taught as a subject in school so that students could achieve foreign language competence (EFL) or if it is being used as a language of instructions in schools and as a lingua franca between speakers of other languages (ESL) (Marckwardt, 1963). Exposure differences where learners use English on a daily basis to communicate with other English speakers as opposed to using it for restricted purposes might affect the language learning process. Also, differences in the nature of the instruction between the two contexts, the materials used, and learners' interaction with native speakers are important factors. 
Knowing whether students in the ESL setting are, in fact, experiencing transfer effects is useful to language instructors. For example, if being an ESL context where exposure to English weakens or eradicates the L1 transfer effect, then ESL language instructors should not be concerned with it. On the other hand, if ESL students experience L1 transfer effects, then language instructors with many Arabic L1 students should start giving this phenomenon some attention. In the following sections, I discuss the three grammatical features I studied.

\subsubsection{Relative clauses}

One of the grammatical feature that is often studied in Arabic CA is relative clauses. These "syntactically-complex structures" are seen as challenging for learners of English (Alotaibi, 2016, p.57). Just like English relative clauses, Arabic relative constructions are dependent constructions that cannot stand on their own (Al-Washali \& Hasnain, 2013).

Arabic relative constructions are different than English relative clauses in many ways. While English relative pronouns are followed by relative clauses, Arabic relative pronouns are followed by constructions called [șila]. These constructions can be clausal or non-clausal, e.g. nominal sentences, prepositional and adverbial phrases (Hamdallah \& Tushyeh, 1998; Touchie 1983). CA literature highlighted the differences between English relative clauses and Arabic relative constructions which influenced student errors. Unlike English, Arabic allows the omission of many elements that are in relative clauses in English, such as the relative pronoun, the main verb within the relative clause and the 
relative clause's head noun. Arabic relative constructions also characterized by the use of resumptive pronouns.

One of the main differences between English and Arabic relatives is that Arabic allows the omission of the relative pronoun. According to Almasri (2013), this feature is very common in Arabic especially if the referent could be inferred from the context. Almasri used the following example which was taken from the Holy Quran, Hood, verse 116:

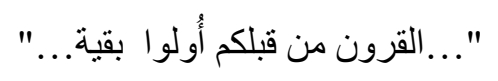

Plquru:n min qablikum ulu: baqijjah

... generations before you those [who] had few...

Almasri explained that although the relative pronoun "who" was deleted because the reader could easily infer the meaning of the deleted relative pronoun "who" from the context. The clause introduced by the demonstrative pronoun "those" refer to the deleted relative pronoun "who." Many studies discussed the deletion of the relative pronoun in cases where the head noun is indefinite (Asfoor, 1978; Hamdallah \& Tushyeh 1998; AlWashali \& Hasnain, 2013; Touchie, 1983). An example of deleted relative pronoun when modifying an indefinite pronoun is:

ra?ajtu radzulan JaSruhu: t'awi:1

I-saw man hair-his long

*I saw a man his hair is thick.

The indefinite head noun "man" was modified by an Arabic relative clause [ fa9ruhu: țawi:1] "his hair is long" that lacked a relative pronoun. The English equivalent requires the use of the mandatory relative pronoun "whose," as in: 
I saw a man whose hair is thick.

English relative pronouns, on the contrary, are only omitted when they occur in "nonsubject gaps in restrictive relative clauses.” (Biber, Conrad \& Leech, 2015, p. 283). Therefore, the deletion of the relative pronouns when it is filling a subject position or when it occurs in non-restrictive relative clauses yields ungrammatical relative clauses.

Arabic also allows the deletion of the verb within the verbal relative construction (Almasri, 2013). As opposed to Arabic relative constructions, English relatives are clausal and they require the presence of verbs. This discrepancy between Arabic and English is a possible source of difficulty as learners might omit verbs within the English relative clause. Some of the relative clause errors reported by Scott and Tucker (1974) were due to the omission of the main verb.

Another element that can be omitted from Arabic relative constructions is the head noun (Touchie, 1983) which is not the case in English. English relative clauses modify head nouns and are obligatory elements. When addressing this characteristic, Touchie claimed that both Arabic and English allow the presence of "free" or "headless" relative clauses. Touchie used the example "Those who took precautions escaped the hurricane" apparently believing cannot act the head noun for a relative clause. However, the head noun is one of the key elements of English relative clauses, and pronouns can act as head nouns (Conrad \& Biber, 2009). The deletion of the head noun then is a characteristic that should be attributed to L1 transfer.

Another characteristic that differentiates of Arabic relatives from English relative clauses is the use of the resumptive pronouns. Arabic [șila] contains a resumptive 
pronoun referring to the head noun that is modified by the relative clause. The resumptive pronoun must agree with the referent in number, person and gender (Almasri, 2013). However, Arabic does not allow resumptives to appear in the subject position (Hamdallah \& Tushyeh, 1998; Jassim, 2011). Using the resumptive pronoun in the subject position as in the example below is ungrammatical in Arabic:

*?ssajjadatu Pallati: kataba-t al-kita:b fa:zat hryə

The-lady who wrote definite marker-book won she

*The lady who wrote the book won she.

This aspect of Arabic has been misinterpreted in at least one study. Scott and Tucker (1974) treated errors made by Arab learners which are caused by using a resumptive pronoun instead of a subject gap as mother tongue interference. Subjects in their study used resumptive pronouns instead of subject and object gaps. The researchers grouped both errors as instances of $\mathrm{L} 1$ transfer adding:

Arabic requires that when a verb has an object a pronominal suffix be attached to the verb agreeing with the object in gender and number. The verb also agrees with its subject in number, gender and person, so failure to delete subjects and objects is attributed to MT [mother tongue] interference. (p.88)

Although the Arabic verb agrees with the subject's gender, person and number, Arabic does not allow resumptives to fill in subject gaps. Arabic does not allow a resumptive pronoun referring back to the subject to be attached to the verb in that case. Hence, relative clause errors that are caused by a resumptive pronoun in a subject gap are not instances of L1 transfer based on CA between Arabic and English, rather intralanguage. Resumptives are obligatory when they appear in the position of: 
1. indirect objects

2. objects of prepositions

3. comparisons

4. and genitives

They are optional in objects (Hamdallah \& Tushyeh, 1998). Hence, learners' attempts to form a relative clause modifying an object might result in resumptive pronouns, e.g.

tasawwaqtu maSa Palfata:t Pallati: Piltaqajtu-ha bilPams

I-went-shopping with the-girl that I-met-her yesterday

*I went shopping with the girl that I met her three weeks ago.

Because the relative construction is a verbal or clausal, the resumptive accusative pronoun [ha] "her" in the previous example was cliticized and added to the verb [iltaqaytu] "met." The resumptive pronoun in nominal relative constructions can be cliticized to a verb as in the previous example, or it can be reduced to a suffix and added to either a noun, preposition, complemetizer (Hamdallah and Tushyeh, 1998). The following examples demonstrates the cliticization of the resumptive pronoun to a noun in a), preposition in b) and a complementizer in c):

a) Plfata:t Pallati: ummu-ha Nu:ra the-girl whoes mom-her Nora

*The girl whose mom her is Nora

b) Pt'aawila Pllati: wad`ą-tu Galkita:b Palaj-ha the-table which I-put the-book on-it

*The table which I put the book on it

c) Palmadatu Pallati: PiStaqadtu Pannaha $\mathrm{s}^{\mathrm{S}}$ aSbatun 
the-course that I-thought that-it hard

*The course that I thought it was hard

The resumptive pronoun [ha], which is equivalent to the English pronoun "her," was cliticized to the noun [ummu] "mom" in example a, and it became [ummu-ha]"her mom." In example b, the pronoun [ha] was cliticized to the preposition [Cala] "on" so it became [Calajha] "on it" whereas in example c the pronoun "it" was cliticized to complementizer [?anna] "that" to form the construction "that-it" [?annaha]. Based on the previous CA, L1 transfer might influence learners to use resumptive pronouns when producing English relative clauses

Many EFL studies investigated relative clause errors made by Arabic learners (Qaid \& Ramamoorthy, 2011; Alhaysony, 2012; Alotaibi, 2016; Alroudhan, 2016). Alroudhan (2016) investigated the erroneous use of resumptive pronouns in a study involving 100 advance EFL students and teachers through an acceptability judgment test. The results revealed that the majority of the sample accepted the use of resumptive pronouns. The CA conducted by the researcher predicted learners' difficulty, and the results confirmed it.

As opposed to EFL studies where relative clauses are frequently investigated, including in the past ten years (Qaid \& Ramamoorthy, 2011; Alhaysony, 2012; Alotaibi, 2016 and Alroudhan, 2016), ESL literature on Arab learners' acquisition of relative clauses has not been updated since the1980s. I could not find a current study that addresses the ESL context. Most of the studies were conducted in the 1970s-80s. For instance, Scott and Tucker (1974) studied oral and written data by 22 Arabic learners and found that the most frequent relative clause error their subjects made was the deletion of 
the relative pronoun, and they attributed it to L1 transfer. Touchie's (1983) analyzed data from 102 Arabic learners and found that L1 transfer accounted for many of the errors that learners made especially in the use of resumptives in forming the relative clause.

Meanwhile, Schachter's (1974) study was especially influential (Touchie,1983). In her study analyzing writings of Arabic, Perisan, Chinese and Japanese ESL learners through CA and EA, Schachter found that Arabic and Persian learners used relative clauses more frequently than the two other groups. The analysis also revealed that Arabic and Persian learners made many errors even though these languages had more similarities to English relativization than Japanese and Chinese. Schachter concluded that:

The learner apparently constructs hypotheses about the target language based on knowledge he already has about his own language. If the constructions are similar in the learner's mind, he will transfer his native language strategy to the target language. (p.212)

The previous quotation means that Arabic and Persian students consulted their knowledge of their L1 to form grammatical constructions that they deem similar to the target language they were learning. The errors found in the data were attributed to learners' reliance on their L1 knowledge in forming relative clauses.

\subsubsection{Passive Voice}

Another grammatical feature that varies between Arabic and English is the passive voice. It is less frequent in Arabic (El-Yasin, 1996). The differences in forming the passive voice in English and Arabic might cause learners difficulty. The absence of 
the auxiliary verb in the Arabic formation of a passive voice could also influence Arab learners' production of ungrammatical passive sentences such as:

*The apple eaten.

correct: The apple was eaten.

*The agreement ratified last week.

correct: The agreement was ratified last week.

Arabic passivization, in contrast to English, is expressed by the means of melodic overwriting "where the vocalic pattern of the active verb changes" (Laks, 2013, p.163). The vocalic pattern of perfective verbs changes to mimic the u-i pattern while imperfective verbs take the u-a pattern. For example, the verb "eat" [ja?kul] follows the u-i pattern in the perfective form when passivized so it becomes: ukila

[?ukila] "was eaten."

[yarkul] simple present tense "eat"

[?ukila] perfective passive

The imperfective form follows the u-a pattern as in [ju?kal] "is being eaten":

[ya?kul] simple present tense "eat"

[yu?kal] imperfective

Moreover, Arabic does not have agentive passives so "there is no natural way of mentioning the doer" (Elyasin, 1996, p.20). A sentence like:

The lightbulb was replaced by Andrew.

would be semantically odd and deemed unnatural because of the by-phrase. Though it can be translated into Arabic, it is difficult to imagine a context for it. Previous research 
on Arab learners' acquisition of English passive voice focused on learners "avoidance" of using passive voice and "delay" in acquiring it the literature overall is "insufficient (Adler, 2012, p. 37). A few studies discussed errors made by Arabic learners when forming passive sentences which were Alotaibi and Alajmi (2015), Kleinmann (1977) and Adler (2012).

As for research on the effect of learners' L1 on their use of the English passive voice, Alotaibi and Alajmi (2015) conducted a study involving 50 advanced Arabic EFL learners. Participants were administered grammaticality judgment tests designed to investigate learners' acquisition of verbs that passivize. The researchers found that positive $\mathrm{L} 1$ transfer helped students answer the questions on the verbs that passivize correctly as those verbs had Arabic counterparts.

Meanwhile, Kleinmann (1977) investigated avoidance behavior in ESL learners whose native languages were Arabic, Spanish and Portuguese in a study that used both $\mathrm{CA}$ and EA. He found that Arabic L1 learners avoided using the passive voice in activities designed to elicit the use of passives. This shows that learners might have found this feature problematic and tried to avoid using it.

As mentioned earlier, the literature on Arab learners' acquisition of the passive voice is limited. Moreover, Kleinmann's (1977) and Adler's (2012) studies were the only studies that addressed an ESL context. Adler's (2012) study investigated passive voice errors conducted by L1 Korean and Arabic ESL students. Adler found that the most common error made by L1 Arab students was "not using an auxiliary verb." Despite the fact that lack of an auxiliary "be" in Arabic is a major difference' between Arabic and English passives, Adler did not attribute that error to L1 transfer. Adler's research 
questions were confirmatory as she relied on studies that focused on either the avoidance phenomenon or the use of the by-phrase by learners. The researcher did not consult CA and L1 studies that investigated Arab learners' omission of the auxiliary (e.g., Scott \& Tucker, 1974) and built her conclusions on the literature that she consulted for her study.

\subsubsection{Definite Article}

Another grammatical features that gets studied more frequently by EFL-oriented studies but is underrepresented in an ESL context is articles (Scott and Tucker 1974, Kharma, 1981; Crompton, 2011; Shalaby 2014). The English article system is different than Arabic. The English article system is made of the indefinite articles "a" and "an", the definite article "the," and the zero article. Arabic, on the other hand, marks definiteness with the use of the definite prefix added to the beginning of nouns [?al], e.g. [Palfilm] "the movie." Arabic has no indefinite articles and indefiniteness is expressed through the absence of the definite prefix (Scott and Tucker, 1974).

The Arabic definite prefix is used more frequently than the English definite article (Alhaysony, 2012). Nasser (1983) listed the uses of the Arabic definite prefix that were different than English. Arabic uses the definite prefix with countable nouns that are used in a generic sense where no gender distinction is made, e.g. "the man" instead of "man" when it is used to talk about humans regardless of their gender. It is also used with abstract nouns, e.g. "the history" instead of history. Kharma and Hajjaj (1997) listed mass nouns when they are used to refer to the whole kind, e.g. "the water" instead of "water," some proper nouns such as "The Kuwait" instead of "Kuwait" English (Cited in Shalaby, 2014). It is repeated when two nouns are conjoined by "and" - e.g., "the book and the 
pen" instead of "book and pen." Such uses of the definite article do not correspond with its use in. Hence, Arabic learners' overuse of the English definite article was documented in several studies. Scott and Tucker (1974), Shalaby (2014) and Alhaysony (2012) are examples of studies where analysis of Arab learners' data revealed the overuse of the definite article. This overuse was attributed to learners' transfer of their L1 knowledge as the definite article was used to replace the zero article.

In a few cases, previous studies have mis-analyzed definite article errors. In particular, some studies (Smith, 2001; Sabbah, 2015; Thyab, 2016) categorized errors like the following as transfer errors:

grammatical construction: the arms of soldiers learner text: *arms of soldiers However, Arabic would use a definite marker in this context although it is added to the second noun in this phrase:

アðrưu Pəl-dzunu:d

arms definite-soldiers

arms of the soldiers

Because Arabic uses a definite marker in these phrases and no definite article was used in this example, it is not accurate to count such errors as transfer errors.

Based on the literature reviewed earlier, the overuse of the definite article, i.e. using the definite article in place of the English zero or indefinite articles is an error attributed to L1 influence. 
As discussed in the section above, the literature on the effect of L1 Arabic transfer acquisition of the English relative clauses, passive voice and definite article is lacking and further investigation is needed.

\subsection{Interviews and L1 Transfer}

While the analysis of learner errors in writing can provide some evidence of transfer, they cannot tell us what went on in the learners' heads. One way to investigate how learners think when they write in English is to have learners talk about their experiences and reflect on them. A few studies used interviews to investigate transfer among second and foreign language learners (Touchie, 1983; Aronin \& Toubkin, 2002). For example, Aronin and Toubkin's (2002) studied transfer in L2 and L3 immersion programs. They investigated the effect of Russian, which was learners' L1, on their acquisition of Hebrew as a second language and English as learners' L3. They also investigated whether L2 and L1 affected learners' acquisition of L3. The interviews, however, were group discussions and although each participant was given time to respond to the questions posed by the interviewer, the fact that the interviews were not carried individually might have affected the overall results. Students might have been tempted to copy each other's responses, especially those who were introverts and might hold back some information accordingly. The researchers said that when asked about Russian's effect on learners' acquisition of L2 and L3, students were "defensive" and responded with comments such "It is my native language. How can it interfere with anything?." The majority of learners participating in their study said that they did not experience L1 transfer when acquiring both L2 and L3. Eighty-five percent said that 
Russian did not interfere with their acquisition of Hebrew and 91\% responded that Russian did not interfere with their acquisition of English.

Touchie's (1983) study was the only study where interviews focused on the influence of Arabic students' L1 influence on their acquisition of a grammar feature, in this case the relative clause. Touchie was looking into the strategies learners adopted in forming relative clauses. The researcher reported interviewing "small groups of Arabic ESL students." It was not clear whether the interviews were carried individually or if they took a form of group discussions. One of the major findings of that study is that Arabic ESL interviewees reported that their L1 influenced their relative clause errors. Eightyeight percent of the participants who were in lower ESL levels reported that they relied on their L1 Arabic in answering four relative clause tests administered by the researcher. Fifty-seven percent of Touchie's participants enrolled in intermediate levels and 19\% of advanced participants reported consulting their L1. After analyzing the Arabic to English translation test along with the multiple choice, sentence completion and grammaticality judgement tests Touchie found that the most frequent error was the use of the resumptive pronoun followed by the omission of the relativizer. Both errors are predicted by CA and attributed to L.

\subsection{Purpose of Current Study}

Previous literature has shown that differences between Arabic learners' mother tongue and English appears to influence some grammatical errors made by Arabic learners of English. The current study is an extension to earlier research. It seeks to investigate L1 transfer in the writings of Arabic learners of English based on CA. I focus 
on the relative clause, the passive voice and the definite article in the writings of Arabic ESL learners. While most error analysis studies focused on Arabic learners of English in an EFL context, I focused on the ESL context.

Only one previous study sought to get learner's view on Arabic L1 transfer and whether they thought it was a factor that influenced their production of L2 constructions. The focus of that study, however, was relative clauses only. Interviews with Arabic ESL learners might help researchers determine whether L1 is, in fact, a factor that influences the acquisition of the grammatical features at hand.

My study addressed the following research questions with respect to relative clauses, the passive voice and the definite article:

1. A) To what extent are these features problematic for students?

B) Is there a statistically significant difference between the frequency of errors caused by L1 transfer and other, non-transfer errors?

2. How do learners describe the influence of their L1? Specifically, in Arabic ESL learners' descriptions, does L1 transfer appear to influence grammatical errors made with the relative clauses, the passive voice and the definite article?

I answered these questions by conducting an EA of Arab ESL learners' writings based on CA. Due to the fact that EA and CA cannot tell us about transfer as a mental process, I interviewed Arab ESL learners to investigate the effect of L1 transfer on their acquisition of the grammatical structures in question. The interviews were intended to facilitate a more thorough understanding of transfer effects than the EA of the written data alone. 


\section{Chapter 3 \\ Methods}

In this chapter, I will address the context of my study, the data that I used to investigate the frequency of the relative clauses, the passive voice and the definite article in the writings of ESL students. I will also discuss the analysis methods, the research tool that I used to investigate whether L1 transfer is a factor influencing these errors, and learners' attitudes towards it.

\subsection{Context of the Study}

The context of my study is the English Language Program (IELP) at Portland State University (PSU) in the U.S. I chose this location because it attracts a large number of Arabic students. Arab students admitted to the program in the academic years 2015/16 and 2016-17 made up 50 percent of the total number of students enrolled. Approximately 185 Arabic speaking students per term were enrolled in the program in the academic year 2015-16 and 140 in the academic year 2016-17 (Horikawa, N., personal communication, April 4, 2017). Learning about the academic writing of this population is, therefore, directly relevant to the instructional work of PSU IELP and will help inform it.

\subsection{Data}

The data that I used is divided into two sets: written papers and interviews. The first set of data was comprised of 50 academic papers written by PSU's IELP's levels 4 Arab ESL learners as part of their Guided Research Writing (GRW) classes. The proficiency level of IELP Level 4 learners in writing and grammar corresponds to Advanced Mid 
Writers level of the American Council on the Teaching of Foreign Language (ACTFL) proficiency guidelines. Learners are expected to have a "good control of the most frequently used target-language syntactic structures" (ACTFL, 2018).

The papers are part of the Guided Research Writing (GRW) corpus compiled by Darby Smith, a former Intensive English Language Program (IELP) instructor at Portland State University. The corpus is made of 476 texts written by 255 students from 10 language backgrounds: Arabic, Chinese, Farsi, Hindi, Japanese, Korean, Portuguese, Spanish, Thai and Vietnamese. There are 249 texts written by Arabic learners of English who were enrolled in 23 classes over five terms period (Summer 2013 - Summer 2014). Students were assigned two research assignments, a rough draft followed by a polished final draft. I used 10 first draft papers from each term for my sample. Because I was looking at transfer, the first draft would be more representative of learners' knowledge as the second draft is usually more refined and incorporates revisions based on instructor's feedback. I analyzed papers that received a passing grade of at least 70, which is a $\mathrm{C}$ on the IELP grade scale to see whether the features investigated were still problematic to this group of learners despite having the language command needed to pass the class. My rationale was that, by eliminating papers that did not get a passing grade, I eliminated students who did not truly meet my proficiency level criterion. Including papers that were below $70 \%$ might have affected the results greatly, especially if it turned out that most of the errors were made by this group of learners.

The second set of data is interviews with five IELP students enrolled in IELP's advanced writing classes. I recruited five volunteer students in Winter 2018 from two participating classes: Level 4 Guided Research Writing (GRW) and Level 5 Independent 
Research Writing (IRW). I decided to include both Level 4 and5 students because higher level students sometimes get placed in Level 4 because they have no experience with a specific skill, such as citing their work with a specific style system, while Level 5 is comprised of students who choose to finish the program instead of testing out (Spitzer, L., personal communication, May 22, 2018). In other words, the difference in proficiency level between levels 4 and 5 is not clearcut. Also, since I wanted to focus on students with advanced writing skills, both IELP levels 4 and5 meet the ACTFL advanced proficiency. Finally, my decision to include Level 5 students was influenced by the fact that few level 4 students signed up for the interviews. Participants filled out consent forms before taking part in the study (Appendix A) which state that subjects will be anonymized. Hence, I assigned each participant a code so that they cannot be identified.

I conducted semi-structured 14-24-minute interviews with the participants and I audio recorded the interview participants' answers and transcribed them. The interviews' questions were meant to elicit student answers to questions on students' experiences in learning English grammar. They were directed towards investigating whether Arabic learners used their knowledge of Arabic grammar to understand English grammar by comparing both languages along with their attitudes towards L1 transfer. Other questions targeted specific grammar features such as the omission of the auxiliary verb in passive voice and the use of resumptives in relative clauses. I provided students with a set of erroneous sentences and ask whether they knew what caused the ungrammaticality and whether they would come up with similar constructions. (See Appendix A for the list of questions.) In order to mitigate the effect of peer influence interfering with students' responses, interviews were carried out individually. At the beginning of each interview I 
told students that they could choose to talk in English, Arabic or both, and told them to stop and ask for clarifications when needed. The rationale behind that is some people feel more comfortable discussing the target language's grammar using their native language while others feel that using the target language is easier.

I also talked briefly about L1 influence and explained that some researchers see it as a hinderance while others view it as a tool that can be manipulated to reach a better understanding of the L2. This introduction served many purposes. First, it was to situate the interview and familiarize subjects with the topic. Second, it was meant to encourage students to express their views as opposed to providing answers which they thought supported the interviewer's hypothesis. Meanwhile, introducing subjects to contradicting views on L1 transfer might help mitigate potential self-image effect. Students might be tempted to avoid associating with L1 transfer due to the effect of prior instruction which might have suggested that the negative effect of transfer equates with not being good learners. Hence, providing students with both opinions and ensuring their anonymity through signing the consent forms might help students reflect accurately on their experiences. Students might feel less pressured to talk about their experiences and knowing that they do not have to distance themselves from L1 to maintain their image as good students.

\subsection{Analysis Procedures}

My analysis was divided into five parts. First, I conducted Error Analysis (EA) on the 50 Arabic ESL learner papers, identifying instances of misuse of the features in question, i.e. grammatical and ungrammatical use of the relative clauses, the passive 
voice and definite articles. This step helped me create error categories based on the data that I was analyzing.

For relative clause and passive voice errors, I looked into learners' attempts to form relative clauses and passive constructions. I analyzed each occurrence of either the relative clause or passive voice to see whether they were accurate or not. I created error categories based on the source of error, e.g. the omission of the relative clause's head noun, wrong main verb inflection within the passive construction and so on. I also tallied errors in each error category.

For the definite article, I started with analyzing all the obligatory contexts of the definite article to see whether the definite article was accurately used by learners and marked cases when learners omitted it. I then looked at the erroneous usage of the definite article which did not conform to the obligatory contexts, i.e., overuse of the definite article. I created error categories based on whether the definite article was used correctly or whether it was omitted or substituted before I tallied the errors in each category.

The second step was to determine which error categories qualified as L1 transfer as predicted by $\mathrm{CA}$ and which were non-transfer that did not meet the L1 criteria. Hence, each error category was either categorized as likely caused by L1 transfer based on CA or as a non $\mathrm{L} 1$ transfer error.

After the errors were coded, I moved to step three where I conducted the quantitative analysis which helped me determine whether these structures were, in fact, problematic for the learners in the sample. I calculated the frequency of accurate usage of 
each grammatical feature, the mean, the median and the mode to examine the frequency of errors in each feature.

Step four was to examine the statistical difference between L1 errors and other errors to see the extent to which L1 transfer was involved in the errors. In order to calculate the statistical difference, I normed the frequency of each error category a count per 1000 words of text for each paper. Then I ran a Related-Samples Wilcoxon Signed Rank Test, a non-parametric test of the differences between the groups. I chose to use this non-parametric test because error distribution was not normal. As for the significance level, I set the alpha at $.017(\mathrm{p}=.017)$ because I ran three tests - one for each feature examined.

The last step in analyzing the written data was to investigate the frequency of L1 errors to that of non-L1 errors in papers that received a final score below $80 \%(\mathrm{n}=24)$ and compare it with the frequency of papers receiving scores of $80 \%(\mathrm{n}=26)$ and above. This step was directed towards examining error trends in both groups of learners, those who managed to get a barely passing grade and those who demonstrate a good command of language.

Since L1 transfer is associated with mental processes, the mere analysis of the written product is not enough to decide whether learners consult their L1, consciously or subconsciously, when producing the error. The last part of this study was, therefore, targeted towards having more insights into what learners report their conscious awareness of and practices for using the grammatical features in question along with their attitudes and their recognition of errors related to the grammatical features I investigated. My analysis of the interviews was shaped by learners' responses to the questions I posed 
(Appendix A) as well as the themes that they brought up when reflecting on their experiences with grammar. Some of the questions asked students to reflect on their L1 transfer habits while writing and whether they were comparing Arabic grammar rules to English and transliterating ideas into English. Other questions asked students to determine whether sentences using relative clauses, passive voice and definite articles were grammatical and whether interviewees were able to recognize L1 transfer errors in those erroneous sentences. The interviews were characterized by detailed description of transfer habits by interviewees who felt comfortable talking about their experiences with L1 transfer. Many interesting themes emerged from the interviews that relate to Arabic and English grammar, differences of English instruction learners received in their home countries and at the IELP, among other themes. I identified three major themes that tie directly to my research question, as described in the results chapter. The interviews helped inform my analysis of the data, especially in interpreting the results and determining whether L1 was a factor that influenced errors in forming the grammatical features in question. 


\section{Chapter 4}

\section{Results and Discussion}

The first part of this chapter addresses the results of my analyses of relative clause, passive voice and definite article errors as well as the analysis of the interview data. The final section summarizes the findings of the written data and the interview data.

\subsection{Relative Clause Errors}

Relative clauses were used in all the papers analyzed. Twenty-three out of 50 papers contained relative clause errors. The accuracy range was large (20\%-100\%) but the accuracy mean was high (90\%) and the median and mode were $100 \%$. The fact that some samples was as low as $20 \%$ and that the accuracy rate in ten papers was $50 \%$ or below this clearly indicates that some students still had problems forming relative clauses. While most of the learners were able to master the formation of relative clauses, there was a group that that was struggling. That group was comprised of nine papers making up $18 \%$ of the data. The percentage of relative clause accuracy for this group of learners was blow $70 \%$.

There were 53 errors distributed among nine error categories. I counted errors caused by the omission of the relative pronoun, the absence the relative clause's main verb, the absence of the noun and the use of the resumptive pronoun as L1 transfer errors based on CA. I divided interlanguage errors into six categories: relative clauses with infinitive or -ing participle errors, relatives as an intended main clause, the deletion of the subject or object within the relative clause, relatives used as intended main clauses and clauses with subject resumptives. 


\subsubsection{L1 Errors}

As for the errors that were potentially influenced by L1 transfer there were 27 errors in the data accounting for $51 \%$ of the relative clause errors overall. Table 4.1 shows the distribution of each L1 relative clause error category and provides examples for each. As shown in (Table 4.1), errors caused by the absence of the relative pronouns were the most frequent. An example of this is the deletion of the relativizer "that" in the example taken from paper 078_MAK1_1042AR. This deletion was probably influenced by L1 transfer as Arabic requires the deletion of the relative pronoun if the relative clause was modifying an indefinite head.

Table 4.1. Categories and raw frequencies of relative clause L1 errors

\begin{tabular}{|c|c|c|}
\hline Category & Example from students' papers & $\begin{array}{l}\text { L1 } \\
\text { Transfer }\end{array}$ \\
\hline Omitted relativizer & $\begin{array}{l}\text { In conclusion, there are several things } \\
\text { have been covered regarding } \\
\text { successful learning ability ... } \\
(078 \text { MAK } 1 \text { _ } 1042 \mathrm{AR}) \\
\text { correct: several things that have been } \\
\text { covered }\end{array}$ & 10 \\
\hline Omitted main verb & $\begin{array}{l}\text { Being in classroom that full of } \\
\text { studenst ... (81_CHE1_1124AR) } \\
\text { correct: that is full }\end{array}$ & 7 \\
\hline $\begin{array}{l}\text { Omitted head } \\
\text { noun }\end{array}$ & $\begin{array}{l}\text {... they will find who will give them } \\
\text { the support and learn through that } \\
\text { mistake. (077_LEA1_1001AR) } \\
\text { correct: those who will give them }\end{array}$ & 5 \\
\hline $\begin{array}{l}\text { Object } \\
\text { resumptives }\end{array}$ & $\begin{array}{l}\text { So we can see here the differences } \\
\text { between all three groups in the time } \\
\text { that they spend it on practice. } \\
\text { (078_LEA1_1024AR) } \\
\text { correct: they time that they spend on } \\
\text { practice. }\end{array}$ & 5 \\
\hline
\end{tabular}




\begin{tabular}{|l|l|l|}
\hline Total errors & 27 \\
\hline
\end{tabular}

The second L1 error category is the deletion of the main verb within the relative clause. This error occurred seven times in four papers' data. The main verb was a copular verb in all the instances. Four of the verb deletions occurred when the verb was proceeded by a predictive adjective. The 81_CHE1_1124AR excerpt (Table 4.1) is an example of copular verb "is" omission.

This error could be attributed to the fact that Arabic allows the deletion of whole relative constructions or parts of them. Also, nominal sentences containing predicative adjectives do not include a copular verb as they do in English. As mentioned earlier, Arabic relative construction could be either clausal or non-clausal.

The third category was the deletion of the head noun which occurred five times in the data. The head noun "those" was deleted in the relative clause in 077_LEA1_1001AR. As I mentioned earlier, this error was treated by earlier as non-L1 transfer (Touchie, 1983); however, the learner's choice to delete the head noun was likely influenced by his/her L1.

The use of resumptive pronouns was the fourth L1 transfer error category also occurring five times in the data. Three of out of the five resumptive errors were due to the substitution of object of preposition gaps with resumptives while two were due to the substitution of direct object gaps. As shown in Table 4.1 above, the learner chose to use the resumptive "it" to modify the referent "time" which is the object of the preposition “in.” This error is likely influenced by the learner's L1 knowledge of relative clauses. 


\subsubsection{Non-L1 Errors}

As for the errors that were not influenced by $\mathrm{L} 1$ transfer, there were 26 errors accounting for $49 \%$ of relative clause errors overall. Table 4.2 shows the distribution of non-L2 errors. The most frequent non L1 errors were clauses that had a grammatical first part but had errors in the second part related to the use of infinitives and -ing participles. Errors in this category appeared nine times in five papers, exemplified in the 080_GLO1_1244AR example (Table 4.2).

Table 4.2. Categories and raw frequencies of relative clause non-L1 errors

\begin{tabular}{|c|c|c|}
\hline Category & Example from students' papers & $\begin{array}{l}\text { Non-L1 } \\
\text { Errors }\end{array}$ \\
\hline $\begin{array}{l}\text { Relatives with } \\
\text { infinitive/ -ing } \\
\text { participle errors }\end{array}$ & $\begin{array}{l}\text { Technology that lets people to share } \\
\text { their problems throw it... } \\
\text { (080_GLO1_1244AR) } \\
\text { correct: lets people share ... }\end{array}$ & 9 \\
\hline $\begin{array}{l}\text { Relatives as used } \\
\text { as intended main } \\
\text { clauses }\end{array}$ & $\begin{array}{l}\ldots \text { the advantages that help people to } \\
\text { find out the information that they } \\
\text { need in internet. } \\
\text { (078_TEC1_1218AR) } \\
\text { correct: ... the advantages help people } \\
\text { to find out the information that they } \\
\text { need in the internet were discussed by } \\
\text { the teacher. }\end{array}$ & 8 \\
\hline $\begin{array}{l}\text { Deleted } \\
\text { subjects/objects }\end{array}$ & $\begin{array}{l}\text { People have been worried about } \\
\text { getting something that lend to } \\
\text { someone...(082_CHE1_1135AR) } \\
\text { correct: that they lend ... }\end{array}$ & 5 \\
\hline $\begin{array}{l}\text { Relatives used as } \\
\text { intended } \\
\text { independent } \\
\text { clauses }\end{array}$ & $\begin{array}{l}\text { Which mean we have to learn we do } \\
\text { something wronge and we have to try } \\
\text { hard to get our goals. } \\
\text { (078_LEA1_1024AR) }\end{array}$ & 3 \\
\hline
\end{tabular}




\begin{tabular}{|c|c|c|}
\hline & $\begin{array}{l}\text { correct: Krakovsky said that they have } \\
\text { to learn from their mistakes, which } \\
\text { means that we have to try hard ... }\end{array}$ & \\
\hline $\begin{array}{l}\text { Subject } \\
\text { resumptives }\end{array}$ & $\begin{array}{l}\text { People who use the positives they will } \\
\text { help the world to move forward. } \\
\text { (080_GLO1_1244AR) } \\
\text { correct: People who use the positives } \\
\text { will help the world to move forward. }\end{array}$ & 1 \\
\hline Total errors & & 26 \\
\hline
\end{tabular}

The second most common interlanguage errors were intended use of relative clauses as main clauses. This error cannot be explained by CA as relative clauses are dependent clauses that cannot stand on their own, and they do not express complete ideas. As shown in Table 4.2 the learner treated the relative clause modifying the subject “advantages” in paper 078_TEC1_1218AR “that help people ....” as a main clause.

The following category was a result of leaving out either subjects or objects within the relative clause as in the example taken from 082_CHE1_1135AR. The subject "they" of the relative clause was deleted in "that lend to someone..." This type of error was not predicted by CA; therefore, I classified it under the non L1 errors.

The fourth error category was caused by using relative clauses as independent clauses that can stand on their own. This category occurred three times in the data. Due to the fact that relative clauses are dependent clauses both in Arabic and English, these errors are not predicted by CA and are treated as instances of interlanguage errors. An example of this category is the excerpt taken from 078_LEA1_1024AR (Table 4.2).

Finally, the last non L1 category was a subject resumptive, which occurred once in the data. As mentioned earlier, Arabic never allows subject resumptives; the use of the 
resumptive in the following example was attributed to interlanguage rather than $\mathrm{L} 1$. The learner used the resumptive pronoun "they" to fill the subject gap in "People who use the positives they will help the world to move forward" (080_GLO1_1244AR).

\subsubsection{Comparison between High and Low-Achieving Students}

The distribution of L1 and non L1 errors between students receiving $80 \%$ and above and those receiving below $80 \%$ varied as shown in Table 4.3 . Fifty percent of the papers that received lower than $80 \%$ had more L1 transfer errors than non-transfer errors, whereas only $36 \%$ of the higher scoring papers had more transfer errors than non-transfer errors. Moreover, 16 out of the 26 papers that received a score of $80 \%$ or above used relative clauses with $100 \%$ accuracy. However, the lowest accuracy rate of relative clause usage in the data (20\%) was also found in this category, and an accuracy rate of $100 \%$ was seen in 11 papers receiving a score below $80 \%$. Overall, the accuracy of relative clause use was higher $(80 \%-100 \%)$ in papers of higher achieving students $(n=23)$ and lower in those of low-achieving papers $(n=11)$. In sum, then, although there is quite a bit of variation, the effect of L1 transfer on relative clause formation seems greater on lowscoring students than on high-scoring students'.

Table 4.3. Relative clause error distribution among papers receiving $80 \%$ and above compared to papers receiving below $80 \%$.

\begin{tabular}{|l|l|l|}
\hline Distribution of errors & $\begin{array}{l}\text { Papers receiving } \\
\mathbf{8 0 \%} \text { and above }\end{array}$ & $\begin{array}{l}\text { Papers receiving below } \\
\mathbf{8 0 \%}\end{array}$ \\
\hline Number of papers with errors & 11 & 12 \\
\hline $\begin{array}{l}\text { Number of papers with higher } \\
\text { frequency of L1 errors }\end{array}$ & 4 & 6 \\
\hline
\end{tabular}




\begin{tabular}{|l|l|l|}
\hline $\begin{array}{l}\text { Number of papers with higher } \\
\text { frequency of non-L1 errors }\end{array}$ & 6 & 4 \\
\hline $\begin{array}{l}\text { Equal distribution of L1 and } \\
\text { non-L1 errors }\end{array}$ & 1 & 2 \\
\hline
\end{tabular}

\subsubsection{Statistical Analysis, Summary and Findings}

The related samples Wilcoxon Signed Rank Test found no statistically significant difference between errors that were influenced by L1 transfer and other errors $(p=.594)$ $(Z=-.533)$. In other words, $\mathrm{L} 1$ transfer is not a significant factor in relative clause errors for these students.

The analysis of relative clauses revealed that learners in this data made errors that could be attributed to L1 transfer and others that were instances of interlanguage. Though there was no statistically significant difference between L1 and non-L1 errors, L1 errors were slightly more frequent. This is evidence of the effect of L1 transfer in influencing learner errors. Moreover, several factors might have influenced the results. I will discuss these factors when I address the analysis of the interviews in section 4.4.

\subsection{Passive Voice Errors}

The passive voice was used in 44 out of the 50 papers analyzed while six papers did not contain any passive voice constructions. There were 32 errors distributed among 15 papers out of the 44 papers where passive voice was used. The accuracy rate of passive use ranged from $0 \%-100 \%$. Mean accuracy was $71 \%$ while the mode and the median were at $100 \%$. Although the accuracy rate was high, the accuracy rate for eleven papers was $50 \%$ or below despite the fact that the sample was written by IELP's Level 4 
students. Students enrolled in GRW were introduced to the passive voice in Level 2 so they have spent at least two terms studying the passive voice in the IELP before moving to Level 4. The accuracy rate, however, shows that although most students used the passive voice accurately, some struggled with it.

There were 32 passive voice errors in the data and they fell into five distinct categories: the absence of the auxiliary verb "be", mis-conjugated auxiliary, wrong main verb inflection, no main verb and the use of the passive instead of the active or the active instead of the passive. Only the first category is due to L1 transfer. It occurred in 11 papers out of the 15 papers containing passive voice errors and accounted for $50 \%$ of the errors. CA between Arabic and English shows that the presence of the auxiliary in the English passive formation and the absence of an equivalent in Arabic makes English passives hard for Arabic learners to acquire.

\subsubsection{L1 Errors}

As shown in Table 4.4, there were 16 instances where the auxiliary was omitted from the passive construction in the data. In the example taken from paper 082_CHE1_1135AR which appears in Table 4.4, the learner dropped "is" from the simple present tense passive construction "nit [not considered]." The omission of the auxiliary resulted in the production of an ungrammatical passive construction. Due to the fact that Arabic passives are created by means of melodic overwriting which does not require the presence of an auxiliary, learners might neglect using it.

Table 4.4. Category and raw frequency of passive voice L1 errors

\begin{tabular}{|l|l|l|}
\hline Category & Example from students' papers & $\begin{array}{l}\text { L1 } \\
\text { Transfer }\end{array}$ \\
\hline
\end{tabular}




\begin{tabular}{|c|c|c|}
\hline $\begin{array}{l}\text { omission of } \\
\text { auxiliary }\end{array}$ & $\begin{array}{l}\text {... students believe that the } \\
\text { informations is readily available so any } \\
\text { one can use it and that nit[not] } \\
\text { considered cheating ... } \\
\text { (082_CHE1_1135AR) } \\
\text { correct: that is not considered cheating }\end{array}$ & 16 \\
\hline Total errors & & 16 \\
\hline
\end{tabular}

The fact that this category accounted for $50 \%$ of the overall passive voice errors is a big indication that the absence of the auxiliary from the learners' L1's passive construction contributed to the ungrammaticality observed in the formation of the passive voice.

\subsubsection{Non-L1 Errors}

As for non-L1 transfer errors, wrong main verb inflection accounted for $24 \%$ of the overall errors and $50 \%$ of the non L1 errors. Table 4.5 below demonstrates the frequency of non-L1 errors as well as examples of each error category. The next non-L1 error category is the use of the passive voice when the active voice is required, which could be attributed to the overgeneralization of the use of the passive voice. This category accounted for $38 \%$ of the passive non-L1 errors as it appears six times. CA does not predict such an error, and it cannot be attributed to L1 transfer because the writer's choice to favor the passive over the active in this context is unacceptable in Arabic too.

Two more error categories accounted for the remaining $12 \%$ of the non L1 transfer errors. Each error category appeared once in the data and accounted for $6 \%$; both categories are verb-related: the absence of the main verb and the use of the misconjugated auxiliary. 
Table 4.5. Category and raw frequency of passive voice non-L1 errors

\begin{tabular}{|c|c|c|}
\hline Category & Example from students papers & Non-L1 \\
\hline inflection errors & $\begin{array}{l}\text { In addition, Computers are being used } \\
\text { for learning, which is now founded } \\
\text { wrong all around the world.... } \\
\text { (089_GLO1_1239AR) } \\
\text { correct: which is now found }\end{array}$ & 8 \\
\hline $\begin{array}{l}\text { attempt of } \\
\text { passive when } \\
\text { active required }\end{array}$ & $\begin{array}{l}\text { Email, Twitter and Blackberry are three } \\
\text { social media programs that most of } \\
\text { people love to use it, people might be } \\
\text { lost their personality. } \\
(078 \text { TEC1_1218AR) } \\
\text { correct: people might lose their } \\
\text { personality }\end{array}$ & 6 \\
\hline $\begin{array}{l}\text { Mis-conjugated } \\
\text { auxiliary }\end{array}$ & $\begin{array}{l}\ldots \text { it is possible that heroism not be } \\
\text { measured by fame ... } \\
\left(080 \_ \text {MAK } 1 \_1067 \mathrm{AR}\right) \\
\text { correct: is not measured }\end{array}$ & 1 \\
\hline $\begin{array}{l}\text { omission of main } \\
\text { verb after } \\
\text { auxiliary }\end{array}$ & $\begin{array}{l}\text {... technology can save people time, but } \\
\text { they use it to waste their time instead } \\
\text { and use it when needed: technology } \\
\text { should be as a supplement... } \\
\text { (082_TEC1_1169AR) } \\
\text { correct: } \text { should be used }\end{array}$ & 1 \\
\hline Total errors & & 16 \\
\hline
\end{tabular}

As for the absence of the main verb as shown in the 082_TEC1_1169AR example, the passive voice construction "technology should be as a supplement" lacks a main verb. The learner's omission of the main verb "used" when attempting to generate the passive verb phrase "should be used" is viewed as an example of learner's L2 knowledge rather than a mother tongue interference. 
The second verb-related error was the use of the wrong form of the auxiliary as evident in the 080_MAK1_1067AR example. Since the auxiliary has no equivalent in Arabic, and the learners demonstrated their knowledge of the existence of auxiliary verbs in the passive formation, this error is attributed to learner's interlanguage interference.

\subsubsection{Comparison between High and Low-Achieving Students}

The distribution of L1 and non L1 errors between students receiving $80 \%$ and above and those receiving below $80 \%$ varied as shown in Table 4.6. The distribution shows that L1 errors were more frequent in more than half of the papers receiving below $80 \%$ while they were less frequent in papers that received $80 \%$ and above. The number of papers with higher non-L1 error frequency was slightly higher in those receiving a score of $80 \%$ and above than those receiving less than $80 \%$ and the same applies for papers with equal frequency of both types of errors. This distribution suggests that the effect of L1 transfer for passive voice is greater for low-scoring learners than for high-scoring learners.

Table 4.6. Passive voice error distribution among papers receiving $80 \%$ and above compared to papers receiving below $80 \%$.

\begin{tabular}{|l|l|l|}
\hline Distribution of errors & $\begin{array}{l}\text { Papers receiving } \\
\mathbf{8 0 \%} \text { and above }\end{array}$ & $\begin{array}{l}\text { Papers receiving below } \\
\mathbf{8 0 \%}\end{array}$ \\
\hline Number of papers with errors & 8 & 7 \\
\hline $\begin{array}{l}\text { Number of papers with higher } \\
\text { frequency of L1 errors }\end{array}$ & 3 & 4 \\
\hline $\begin{array}{l}\text { Number of papers with higher } \\
\text { frequency of non-L1 errors }\end{array}$ & 3 & 2 \\
\hline $\begin{array}{l}\text { Equal distribution of L1 and } \\
\text { non-L1 errors }\end{array}$ & 2 & 1 \\
\hline
\end{tabular}

Moreover, 16 papers out of the 26 papers that received a score of $80 \%$ used the passive voice with $100 \%$ accuracy while only two papers did not include the use of the 
passive voice. Meanwhile, an accuracy rate of $100 \%$ was seen in 13 papers receiving a score of below $80 \%$ while the passive voice was not used in four papers. The overall accuracy of passive voice use was higher for higher scoring students and the avoidance of passive usage was lower in that group of learners. This distribution suggests that L1 transfer might affect low-achieving students' formation of the passive voice more than it does high-achieving learners.

\subsubsection{Statistical Analysis, Summary and Findings}

Based on the related-samples Wilcoxon signed rank test, there is no statistical difference between errors caused by L1 transfer and errors cause by non-L1 transfer ( $p=$ .504) $(Z=-.668)$. The results reported above show that the passive voice was a problematic feature for 15 learners. The accuracy rate was below 50\% in seven papers even though students were introduced to the passive voice early on in the program and were now enrolled in upper-level classes. Only one category accounted for L1 errors which is the absence of the auxiliary "be" as it contributed to $50 \%$ of overall passive errors. However, there was no statistical difference between L1 and non-L1 errors.

As for the six papers that did not include passive voice constructions, they accounted for $12 \%$ of the overall data analyzed which is not a high percentage. One could argue that avoidance influenced learners' choice to refrain from using the passive voice. However, as discussed earlier, Arabic does not favor passives, so this also could have influenced learners' choice not to use it. In other words, absence of passives could be a transfer issue. It was impossible to measure this effect, however. 


\subsection{Definite Article Errors}

The definite article was used in all 50 papers analyzed. Out of the 1,541 obligatory definite article contexts, 1044 were accurate. The accurate uses accounted for $68 \%$ of the overall obligatory contexts. Only one paper was free of errors and only four other papers had an accuracy rate that was $90 \%$ or above. As for the accuracy range, papers varied from $5 \%-100 \%$ while the mean was $67 \%$, the median $73 \%$ and the mode $86 \%$.

As shown from the results introduced above, definite articles are still a source of error for participants in this data. The fact that the accuracy rate for some learners was as low as $5 \%$ proves that the definite article was problematic for the participants although it is one of the first features to be introduced to learners.

There were 497 definite article errors. They fell into three categories:

1. article insertion, i.e. when the definite article filled the place of either the indefinite or zero article.

2. article omission.

3. article substitution by the indefinite article.

Consistent with the review in chapter 2, I classified errors that were caused by the insertion of the definite article to L1 transfer, while deletion and substitution errors were counted as non-transfer errors.

\subsubsection{L1 Errors}

The insertion of the definite article occurred 230 times in the data, accounting for $46 \%$ of all definite article errors. This error occurred in 43 papers out of the 50 papers analyzed. A typical example is the one in Table 4.7, where the learner inserted the 
definite article "the" in front of the noun "globalization," which is both noncount and abstract and does not require an article. This error corresponds with the way the definite prefix in Arabic is used with the noun "globalization." Hence, this error is attributed to L1 transfer.

Table 4.7. Category and raw frequency of the definite article L1 errors

\begin{tabular}{|c|c|c|}
\hline Category & Example from students' papers & $\begin{array}{l}\text { L1 } \\
\text { Transfer }\end{array}$ \\
\hline $\begin{array}{l}\text { Definite article } \\
\text { insertion }\end{array}$ & $\begin{array}{l}\text { The globalization contributed to } \ldots \\
\text { (083_GLO1_1249AR) } \\
\text { correct: Globalization contributed to } \\
\text { develop technologies. }\end{array}$ & 230 \\
\hline Total errors & & 230 \\
\hline
\end{tabular}

\subsubsection{Non-L1 Errors}

As for non-L1 errors, the most frequent non-transfer error was definite article deletion (Table 4.8). It occurred 257 times in the data, which is $52 \%$ of all definite errors. This high percentage can be explained by examining the distribution of errors within papers. An example of definite article deletion is shown in Table 4.8. The learner deleted the definite article preceding the noun "professor" which cannot be attributed to L1 as the Arabic equivalent requires the use of the definite article.

Table 4.8. Categories and raw frequencies of the definite article non-L1 errors

\begin{tabular}{|l|l|l|}
\hline Category & Example from students' papers & Non-L1 \\
\hline $\begin{array}{l}\text { Definite article } \\
\text { omission }\end{array}$ & $\begin{array}{l}\text { and that absolutely encourage student } \\
\text { to cheat because it is difficult for } \\
\text { professor to deal with more than... } \\
\text { (076_CHE1_1131AR) }\end{array}$ & 258 \\
& $\begin{array}{l}\text { correct: ... it is difficult for the } \\
\text { professor }\end{array}$ & \\
\hline
\end{tabular}




\begin{tabular}{|c|c|c|}
\hline $\begin{array}{l}\text { Definite article } \\
\text { substitution }\end{array}$ & $\begin{array}{l}\text { Yunus (2003), a founder of landing } \\
\text { small money to entrepreneurs program } \\
\ldots\left(082 \_ \text {GLO1_1250AR }\right) \\
\text { correct: the founder ... }\end{array}$ & 9 \\
\hline Total errors & & 267 \\
\hline
\end{tabular}

The second non-transfer error was the substitution of the definite article with an indefinite article as in the example taken from 076_CHE1_1131AR. This category accounted for only $2 \%$ of definite article errors, occurring 11 times in the data. Due to the fact that Arabic does not have indefinite articles, this error was listed under non-L1 transfer errors. Together with the article deletion, definite article substitution accounted for $54 \%$ of define article errors.

\subsubsection{Comparison between High and Low-Achieving Students}

The distribution of L1 and non L1 errors between students receiving $80 \%$ and above and those receiving below $80 \%$ varied as shown in Table 4.9. The distribution shows that L1-related errors were more frequent than non-L1 errors for $46 \%$ of the higher scoring papers (12 of 26) and 39\% of the lower-scoring papers (9 of 23). Moreover, the only paper that did not contain definite article errors received a score below $80 \%$. Overall, then, the effect of L1 transfer on definite article errors appears greater for high scoring students than for low-scoring students.

Table 4.9. Definite article error distribution among papers receiving $80 \%$ and above compared to papers receiving below $80 \%$.

\begin{tabular}{|l|l|l|}
\hline Distribution of errors & $\begin{array}{l}\text { Papers receiving } \\
\mathbf{8 0 \%} \text { and above }\end{array}$ & $\begin{array}{l}\text { Papers receiving below } \\
\mathbf{8 0 \%}\end{array}$ \\
\hline Number of papers with errors & 26 & 23 \\
\hline
\end{tabular}




\begin{tabular}{|l|l|l|}
\hline $\begin{array}{l}\text { Number of papers with higher } \\
\text { frequency of L1 errors }\end{array}$ & 12 & 9 \\
\hline $\begin{array}{l}\text { Number of papers with higher } \\
\text { frequency of non-L1 errors }\end{array}$ & 11 & 12 \\
\hline $\begin{array}{l}\text { Equal distribution of L1 and } \\
\text { non-L1 errors }\end{array}$ & 3 & 2 \\
\hline
\end{tabular}

\subsubsection{Statistical Analysis, Summary and Findings}

The related samples Wilcoxon Signed Rank Test found no statistically significant difference between errors that were influenced by L1 transfer and other errors $(p=.128)$ $(Z=1 .-523)$

The percentage of definite article misuse in the data was $32 \%$. It included $98 \%$ of participants which suggests that this grammatical feature is still problematic for learners. However, the statistical analysis showed no difference in the frequency of transfer-related and non-transfer-related errors. Also, high writing scores did not correlate with accurate low frequency of L1 definite article errors.

\subsection{Interviews}

In this section, I focus on my findings based on interviewing five upper-level Arabic L1 IELP students enrolled in Levels $4 / 5$ writing classes. The interviews provided evidence for students' transfer habits, the effect of instruction (which ties into students' attitudes towards transfer) and the effect of students' IELP level on the frequency of L1 transfer errors they made. These were the three major factors that were apparent in the interviews. Students' transfer habits influenced their production of L1 errors. The 
instruction and students' level, on the other hand, helped students reduce the effect of L1 transfer when using some of the grammatical features investigated. For anonymity, the five interview participants are identified as codes.

\subsubsection{Students' Transfer Habits}

As for students' transfer habits, all five students admitted to thinking in Arabic when writing and speaking in English. This is strong evidence of transfer. For example, when I asked student Participant (5) whether expressing ideas in English was easy, the student responded by saying "I don't think so because there is like you have to translate everything in your mind." Meanwhile, Participant (1) said that it was easy for her to express herself in English as long as she did not have to talk about specific things "I think it is easy just to express myself in ... just a little just like basic information about myself, but maybe I can't talk in specific things or more details." She admitted that she always thinks in Arabic when trying to express herself both orally and in writing. All five students that I have interviewed said that they would think in Arabic when expressing themselves in English especially when they are under pressure. Participant (3) for example, said that thinking in Arabic was easier especially with approaching deadlines, and when she wanted to make sure that she could finish her assignments in time.

When asked about the frequency of student's translation of Arabic ideas into English, Participant (5) replied "Most of the time because I get used to it [thinking in Arabic first]." The student said that she was not using the strategy of thinking in Arabic and translating ideas into English as much in writing. She explained that she did not feel the need to refine her writing and expressing her ideas using proper grammar because 
"Everybody do it [makes grammar mistakes]. Even like Americans do it, so I think it's fine."

Another student Participant (4) said that although he was thinking first in Arabic all the time, he was aware that "sometimes [his writing] doesn't really make sense ... it [translating ideas from Arabic] doesn't make it really like English.” Participant (2), on the other hand said that she would always brainstorm first in Arabic, she said that strategy helped her "express [ideas] in high level in Arabic and then translate to English. If I want write the essay in English directly I write in lower level like baby." However, she admitted that she would often end up with sentences that contained errors influenced by her L1 as they were pure transliterations of Arabic.

Meanwhile, Participant (3) admitted resorting to translating Arabic ideas, especially when she was under pressure, because "it is easier to think in Arabic." Other students found that comparing both languages helped them get a better grasp of the English grammar. Participant (2) found comparing English to Arabic grammar especially helpful, adding that comparing was something that she did most of the time. This occurred for students even when they said they did not "know" the rules of Arabic grammar well. Participant (4) admits to comparing English rules to Arabic rules despite being told not to athink, translate or compare the two languages, even though he said that he was "not really good at our grammar ... Arabic grammar." Participant (4) was referring to his explicit grammar knowledge, but he was transferring his implicit knowledge of grammar to English although he did not know how to explain the rules. For example, he knew how to form relative clauses in Arabic, but did not know how to explain the underlying rules. 
Students' responses support the claim that L1 transfer is a factor influencing students' errors. The students were clearly still relying on the translation of ideas in their L1 to English, which resulted in the production of L1 transfer errors.

While students in the Aronin \& Toubkin (2002) study wee defensive about the effect of their L1 and ruled out the possibility of transfer, students in this study felt comfortable talking about their transfer habits though admitting that they were instructed not to. This difference could be attributed to social factors or whether learners were viewing their L1s as identity markers, and while this topic is intriguing, it is not the focus of this study.

\subsubsection{Effect of Instruction}

While students' transfer habits affected the production of likely L1 errors, the instruction they received had two main counter effects. The first was that students' attitudes towards transfer were influenced by those of their instructors. All five students interviewed said that were told either by IELP instructors or other language instructors to stop thinking in Arabic while writing in another language. Participant (1) recalled being advised by a French instructor not to think in Arabic. "You have to think in French" is what her instructor used to say. Participant (5) also mentioned her IELP instructors" "just think in English" phrase, adding that her instructors tried to keep both languages separate from each other.

This was reflected in the way students viewed transfer. Students' attitudes towards transfer were negative despite admitting to occasionally relying on it. For example, Participant (1) expressed her negative attitude towards transfer by saying "I 
think this [thinking in Arabic] is a mistake." She explained by saying that the Arabic structure is different than English. This was evident for all students as they emphasized the differences between Arabic and English which encouraged them to view transfer as a negative strategy.

The second effect of instruction was that instruction made students aware of transfer and helped them avoid transfer-related errors. All students reported receiving instruction that was influenced by CA. Instructors who were familiar with the literature of Arabic-English CA pointed out likely L1 errors that Arabic L1 students made. Other instructors were also observant, and they would ask Arabic L1 students about the way certain grammatical features were formulated in Arabic whenever they saw that such an error persisted in the writing of Arabic L1 students. Learners explained that their teachers would ask "Is that the way you do it in Arabic" which was an attempt to decide whether the error was attributed to L1 transfer. Teachers brought their learners' attention to L1 transfer influence on their inaccurate use of English grammar.

As for the effect of this kind of instruction, it seems to yield positive effects such as helping students notice their mistakes and reduce the frequency of L1 errors accordingly. For example, Participant (5) said that her IELP instructors helped her see the difference between Arabic and English passives, relative clauses and noun clauses. This helped reduce her errors, especially that she used to "drop verbs from sentences," including auxiliary verbs. Four out of the five students interviewed believed that CAinformed instruction was useful as it helped them understand the rules and do better. One student said that CA should be used only when conventional instruction fails to stop learners from committing L1 errors. She added that CA-instruction should be provided to 
learners who were struggling and do not seem to differentiate between the Arabic and English grammar.

Students responses suggest that CA-informed instruction not only helps students learn new vocabulary, but as in Laufer and Nany's (2008) study mentioned earlier, CAinformed grammar can also help students learn grammar and avoid L1 errors.

After questioning students about the effect of CA, I presented them with sentences that had errors in relative clauses and passive voice (Appendix A). As for the relative clause errors, two students out of five recognized the use of resumptive pronoun errors, one student did not recognize the error. The discussion of relative clause errors came up earlier in the interview with two of the interviewees. When discussing it, Participant (1) said "I don't think this error is common in my writing." When asked about the L1 errors and thinking in Arabic while writing in English, Participant (2) mentioned that using the resumptive pronoun was one of the most frequent L1 errors in her writing. Instruction helped students notice their use of resumptive pronouns.

As for the passive voice errors, three students were able to pinpoint the absence of the auxiliary verb while two other students failed. Participant (5) commented on his inability to recognize the error by saying "I always forget the be-verb!" When I provided her with the right answer, Participant (2) laughed and tried to provide an explanation of the error; she switched to Arabic and said that because the theme was inanimate, it needed to be in the passive: "The house cannot build itself!" Finally, four of the five students interviewed did not recognizes the definite article error and when I asked them to translate it in Arabic, they all used the definite article before the noun "globalization." Participant (4) said that his teachers would always ask him for the reason that he was 
overusing the definite article while Participant (5) commented on definite article errors by saying that her teachers would delete extra articles from her writings.

Meanwhile, Participant (2) brought up another issue related to the effect of instruction and proficiency tests on her use of complex grammatical features such as the relative clauses. She pointed to the fact that she would get overwhelmed due to writing rubrics that she had to meet for class assignments and IELTS test essays. Both dictated using complex structures, e.g. complex sentences such as those containing relative clauses, to demonstrate writing skills mastery. Her focus on using these complex sentence structures to demonstrate her knowledge of grammar and her mastery of writing would usually influence her production of L1 transfer errors, such as dropping the relative clause's main verb. Instead of being given credit for using complex structures, she would get marked down for committing L1 errors. She complained that such rubrics made her focus on form while ignoring other elements including the meaning that she was trying to convey and the flow of the information she was presenting.

The discussion of the effect of instruction coupled with students' level - which I will cover next - helps explain why there was not a statistical difference between L1 transfer and other errors.

\subsubsection{Effect of Students' Level}

In the interviews, the students reported that they had either stopped or tried to avoid making errors that were predicted by CA, e.g. using the definite article when it is not required, using the resumptive pronoun to fill object gaps and omitting auxiliary verbs from the passive verb phrase. They stressed the fact that they "used to" make these 
mistakes and that their command of English and especially grammar was better than it used to be when they were in lower IELP levels. An example of that is the excitement Participant (3) expressed when she talked about how her instructors nowadays would tell her how "great" her grammar was, although, she admitted, relative clauses were still challenging. More exposure to language also influenced the student's grammar knowledge: "sometimes ... um ... I know there is error here... this is not good but don't ask me why, I don't know, I just fix it because maybe I always hear this in that way so... but I don't know why I just say no this is not right.” This suggests that being an ESL setting with more exposure to English helped the student develop an intuition for grammaticality.

As for Participant (5), whose main struggle was omitting verbs, she said that the frequency of such an error in her writing dropped from $50 \%$ to $6-8 \%$. She also said that she was translating less into English when uttering English sentences that she did when she first joint the program. Hence, both instruction and students' level influenced the frequency of L1 transfer errors in students' writings.

Students' remarks fall in line with the findings of Touchie's (1983) study, in which learners enrolled in lower level ESL classes reported more reliance on L1 transfer in answering relative clause questions on four tests. Therefore, this study supports the fact that transfer is "developmental and tends to become less frequent in advanced stages of second language proficiency pp" (pp. 139-140), although the results for definite articles in this study suggest more research is needed.

As opposed to CA and EA which helped analyze the data produced by learners and not what was going on inside their heads, interviews provided insight into students' 
mental processes which were directly tied to L1 transfer. Students talked about their L1 transfer strategies which involved both translating ideas from Arabic into English and comparing English grammar to Arabic grammar. This makes it likely that errors that were predicted by CA were, in fact, instances of L1 transfer. Instruction on the other hand, had two effects: one was the negative attitude of students towards the L1 while the other was helping students become more aware of L1 errors and trying to overcome them. The level that the students were at and the instruction they had received appears to have affected the frequency of L1 errors in the data and helped students have better grammar knowledge and avoid making such errors.

\subsection{Summary of Written Data and Interviews}

The analysis of the written data did not yield a statistical difference between likely L1-influenced errors and other errors in students' use of definite articles, relative clauses, and passive voice. The examination of high and low-achieving students suggested that higher scores on writing assignments corresponded with lower frequency of L1 errors for relative clause and passive voice errors. The definite article was the only feature where such a relationship did not exist.

The interviews provided insight into students' transfer habits. Student comments suggested even students who were enrolled in upper IELP classes were still influenced by their mother tongue. Factors such as instruction and the level students were at in the IELP helped raised students' awareness of L1 transfer errors which helped students either overcome or minimize the frequency of errors. Although occasional CA-informed 
instruction as well as the level students were at helped students improve their grammar skills, some L1 errors persisted.

While some researchers have argued for teaching strategies based on CA, others contested them. Most students in this data found CA-informed instruction helpful, especially with the grammatical structures they perceived to be difficult (such as relative clauses) or confusing (such as the article system and the passive voice). Students' performance investigated by EA in my thesis study provided a positive effect of CAinformed instruction in reducing L1 transfer errors.

The next chapter will address the limitations of my study and suggestions for future studies as well as concluding remarks. 


\section{Chapter 5}

\section{Conclusion}

In the previous chapters, I reviewed the literature on the effect of L1 transfer in influencing errors made by Arabic L1 learners of English when using the definite article, relative clauses and passive voice. I also explained the goals of my study and the methods I used to investigate the influence of L1 transfer in the production of errors as well as learners' transfer habits and their attitudes. Then, I presented the results of my analyses and my findings. In this chapter, I review my research goals and provide a summary of my findings, and then discuss the pedagogical implications and limitations of my study. In the final section of this thesis, I offer suggestions for future research on Arabic students' L1 transfer.

\subsection{Research Questions and Summary of Findings}

My study was directed towards investigating the effect of L1 transfer on advanced Arabic ESL learners' accuracy using the definite article, relative clauses and passive voice. The second goal was to investigate the influence of L1 transfer as learners perceived it. The questions that my thesis addressed were:

1. A) To what extent are these features problematic for students?

B) Is there a statistically significant difference between the frequency of errors caused by L1 transfer and other, non-transfer errors?

2. How do learners describe the influence of their L1?

In order to answer my first research question on how problematic these features were to students, I analyzed papers written by students enrolled in the IELP Level 4 
Guided Research Writing (GRW). When I analyzed the papers, I found that the mean accuracy of relative clause use was as high as $90 \%$ while the passive voice was at $71 \%$ and the definite article at $68 \%$. Even though the means of accuracy were fairly high, especially for relative clauses, the ranges of accuracy of the features were $20 \%-100 \%$, $0 \%-100 \%$ and $5 \%-100 \%$ respectively. This shows that while some students were able to use these grammatical features accurately, other students were struggling.

As for the main findings related to relative clauses errors, $\mathrm{L} 1$ transfer errors were slightly more common than interlanguage errors although there was no statistically significant difference between L1 and non-L1 errors. The omission of the relativizer was the most frequent transfer error. This falls in line with the findings of Scott and Tucker (1974) who found that the most frequent relative clause error in their data was the omission of the relative clause. While Touchie's (1983) study found that the use of the resumptive pronoun was the most frequent error in her data, resumptive pronouns accounted for $8 \%$ of the errors in the data I analyzed. This low percentage might be the result of the CA instruction students received.

Meanwhile, passive voice errors were equally distributed across both error factors - L1 and interlanguage - each accounting for $50 \%$ of overall passive errors. I found that, while interlanguage errors were divided into four categories, three verb-related and one that had to do with the use of the passive instead of the active voice, there was only one L1 category that was as frequent as all interlanguage categories: the omission of the auxiliary verb. This also suggests that, though L1 transfer was not the most significant factor of passive voice errors, it does influence learners' errors nevertheless. 
As for the definite article, most of the learners in this data analyzed made errors while using this feature. Only $2 \%$ of the papers analyzed did not contain definite article errors. This suggests that Arabic Advanced Mid ESL students found this feature problematic. The overuse of the definite article was the only error category that was counted as L1 transfer, and it was the second most common article error, accounting for $46 \%$ of overall definite article errors. The overuse of the definite article was also documented as the most frequent article error in the data analyzed by Shalaby (2014) of Arabic EFL students. Although L1 transfer errors were slightly less frequent than interlanguage errors, L1 transfer appears to influence students' definite article usage.

Moreover, when analyzing the frequency of L1 errors in papers that received a score below $80 \%$ in comparison to those receiving $80 \%$ and above, result suggested that L1 transfer errors in the formation of relative clauses and the passive voice were more common in papers receiving scores below $80 \%$. The analysis of the definite article did not show such a relationship between learners' writing scores and the frequency of L1 transfer errors.

Overall, the analysis of the written data helped me answer my first research question about the frequency of errors which helped me determine how problematic the features were to that group of students. The analysis of the written data also helped me compare errors that are attributed to L1 transfer to non-L1 errors. I found no statistical difference between errors that were attributed to L1 transfer and non-L1 transfer errors. The analysis revealed that $\mathrm{L} 1$ transfer did influence Arabic learners' relative clause, passive voice and definite article errors, but those errors were not more common than all other errors. 
Transfer is a mental process, and the analysis of learner data through EA and CA alone may not be enough to describe L1 transfer phenomena. Therefore, I used my second method of data collection, interviews with learners, to further explore evidence of transfer. The interviews helped elicit information about learners' transfer habits and their attitudes towards transfer. Learners admitted to thinking in Arabic while writing in English, which influenced their production of erroneous definite article, relative clause and passive voice construction. When interviewed, Participant (5) said that expressing oneself in English was not easy, adding "you have to translate every single $[\ldots]$ in your mind." This learner was in the highest IELP level. In her study, Touchie (1983) found that only a small percentage of the advanced learners - only $19 \%$ - she interviewed reported that their L1 influenced the ways they answered question on tests while the percentage was higher for students who were less proficient. Meanwhile, all five students interviewed in this data were advanced ESL students.

Moreover, learners in my study also noted that receiving CA-informed instruction made them aware of the effect of their L1 on their production and helped reduce the frequency of L1 errors. The fact that IELP instructors were keen on pointing out L1 errors to their students and making them aware of them might have influenced the results of the written data - for example, the low percentage of resumptives in the data as opposed to the high frequency of resumptives in Touchie's (1983) investigation.

\subsection{Pedagogical Implications and Applications}

When I initially designed this study, I anticipated that the frequency of L1 transfer errors in using the definite article, relative clauses and passive voice constructions would 
be much higher than that of other errors. I came to this conclusion after conducting my pilot study. As the current study shows, learners' errors caused by L1 transfer were as frequent or at times slightly more frequent than interlanguage errors; however, there was a great deal of individual variation and the frequency differences were not statistically significant. The interviews showed that students did "think in Arabic" but many had learned not to transfer features if they were ungrammatical in English. Learners in this study received some CA-informed instruction and managed to reduce their L1 errors. The IELP instructors' strategy appears to yield positive results. Since some learners still had high frequencies of L1 transfer errors, however, I suggest even more emphasis should be placed on CA-instruction in order to improve Arabic L1 learner's acquisition of the grammatical features studied. Since students might not be aware of the ways in which negative transfer works, deliberate attention might be key. Supporting the instruction with comparisons between students' L1 and L2 might help students better understand and acquire problematic grammatical features that are prone to L1 interference. A performance assessment followed by corrective feedback is also crucial; so is raising awareness as to potential sources of errors. Hence, identifying sources of learners' errors either by teacher-conducted EA or through consulting the CA-informed EA literature and preparing CA-informed materials might help minimize L1. Students in this data said that they were able to witness the effect of this type of instruction in improving their grammar knowledge which helped them avoid L1 transfer errors.

Also, a comparison is needed between the errors made by ESL and EFL students in the use of the definite article, relative clauses and passive voice contexts. The 
researcher could investigate the effect of variables like instruction, language exposure, teacher's language background, contact with native speakers and so on.

Another issue that emerged from the discussion of the effect of instruction was the fact that at least one learner felt pushed to use certain grammatical features to demonstrate her writing ability. Participant (2) said that writing assignments instructions required her to use a certain set of complex and compound sentences and focusing on producing long complex sentences made her commit L1 errors where she would "miss the verb" for example. Instead of being commended for trying to use complex sentence structure, she would get marked down for producing L1 errors. Although academic writing does require accurate structure, students' attempts to try new structures should be rewarded, not punished. Participant 2's remarks suggest that L1 transfer errors might be the result of students' determination to try new complex structures, which might results in their relying more on familiar L1 structures.

Due to the fact that non-L1 errors were at times as frequent as L1 errors and at times more frequent, instructors should also provide students with more practice for errors that are not likely influenced by their L1. When I was teaching grammar at the IELP in Winter and Spring 2018, students kept asking me for more practice as it helps them internalize grammatical features. Practice can be provided in the classroom or as part of students' homework. Instructors could also direct learners towards extracurricular resources such as textbooks, cellular phone and computer applications that help them practice and improve their grammar skills.

While on paper, "think in English" is a good strategy for language learners, this is not what language learners in this study were doing. Despite the fact that students were 
told to think in their L2 and abandon comparisons with their L1, students could not follow that advice. All students reported using their L1 one way or another. While the ultimate goal is to have students master the language and display native-like grammar performance, instructing students to stop thinking in their L1 clearly did not help students think in English. On the contrary, it created some kind of inner resistance as students kept doing it while acknowledging that it was "wrong." Teachers should avoid associating students' L1 with negative effects. They should provide their learners with concrete examples from learners' own writing to help demonstrate the effect of their L1 through the use of CA. This way, students will know what type of errors to look for when editing and proofreading their papers.

The following implication is inspired by remarks made by one of the students that I interviewed for my thesis study. Participant (3) said that she felt that her exposure to English has helped her develop intuition for grammaticality. She said that she could tell when a sentence is ungrammatical, but she would not know how to explain why. Many second language acquisition theorists have discussed the importance of exposure to the L2 over time and have acknowledged the fact that the teacher cannot provide all the exposure that a learner's needs. One of the language instructor's priorities should be to present students with opportunities that maximize their exposure to the target language outside of the classroom and encourage autonomous learning.

\subsection{Limitations and Future Research}

I analyzed 50 papers for this study. While the results provide useful insights, the sample cannot be taken as being representative of all IELP students or all ESL students. 
Moreover, I could only interview five advanced learners, which is also not representative of all advanced Arabic IELP students. Analyzing a larger set of papers and interviewing a larger number of participants would help provide more insights into the effect of learners' L1 transfer habits.

Also, I analyze papers that received a passing score of $70 \%$ and did not investigate errors in papers that did not. A future study could come up with a more refined method where papers are categorized into failing, just passing and those receiving high grades and investigate whether scores correlate with the accuracy of grammatical features' usage.

The focus of my study was an ESL context in one language center, thus the findings of this thesis study are not applicable to all Arabic ESL students. Furthermore, I included only papers that received a passing grade, so the results cannot be generalized to students who did not get passing grades.

Also, I investigated students' L1 habits and their attitudes towards L1 transfer, but I did not investigate teachers' use of CA, their attitude towards using it and its effectiveness and applicability. A future study could be replicated to investigate teachers' attitudes towards L1 transfer, whether they use CA in their instruction and whether they found it to be an effective and applicable method.

Another study could investigate the effect of CA instruction compared to more conventional types of instruction in a longitudinal study that documents students' progress from novice or intermediate levels to the more advanced to help decide which method is more effective. The researcher could also examine teachers' attitudes and the effectiveness of CA instruction which might help enrich the field. 
Also, a comparison is needed between the errors made by ESL and EFL students in the use of the definite article, relative clauses and passive voice contexts. The researcher could investigate the effect of variables like instruction, language exposure, teacher's language background, and contact with native speakers, analyzing whether these factors correlate with the frequency of errors in the ESL and the EFL contexts.

Finally, many grammatical features were problematic in the sample that I analyzed and are worth investigating. One of the features was phrasal and prepositional verbs. The prepositions and the particles learners used corresponded with those used in Arabic but were erroneous in English, e.g., "contribute in" instead of "contribute to." Wrongly formed noun phrases due to either plural issues (e.g., "many pressures" and "jobs opportunity") or inaccurate modification of the head noun (e.g., "economy job") were problematic for more than $50 \%$ of the learners in this data. Twenty-six papers contained ill-formed noun phrases. Future studies could help inform the instruction further by investigating errors with phrasal verbs, prepositional verbs, and noun phrases and whether they are attributed to learners' L1.

\subsection{Conclusion}

Despite the limitations of my thesis study, it provided insight into L1 transfer in the writing of Arabic ESL learners and insight into learners' L1 habits and their attitudes towards transfer, which was inspired by that of their instructors. This study helps language instructors identify sources of errors influencing Arabic ESL learners' inaccurate production of the definite article, relative clauses and passive voice. It also 
sheds light on the possible benefits of integrating CA-informed instruction into language classrooms.

In conclusion, as a former advocate of the "Think in English" strategy, I feel obliged to acknowledge its lack of validity and applicability. Providing students with such a vague and ambiguous instruction does not help them eliminate or even mitigate the effect of their L1 on their production of their L2. Instruction that is informed by CA provides learners with concrete examples of ways of which their L1 might hinder their L2 accuracy. I now believe that CA instruction, paired with more exposure to the L2, is one of the solutions that helps eradicate the negative effects of L1 transfer. 


\section{References}

ACTFL proficiency guidelines (2012). American Council on the Teaching of Foreign Languages (ACTFL). Retrieved from https://www.actfl.org/

Adler, E. (2012). Investigating L1 Arabic and L1 Korean acquisition of the passive voice in L2 English (Unpublished master's thesis). University of Pittsburgh, Pittsburgh.

Al-Ghamdi, H. M. E. (2016). A contrastive linguistic analysis of Arabic conjunctive nouns in their syntactic structures and their English counterparts. Umm Al-Qura University Journal of Languages and Literatures, 16, 7-49. Retrieved from https://drive.uqu.edu.sa/_/jll/files/16/7.pdf

Alhaysony, M. (2012). An analysis of article errors among Saudi female EFL students: a case study. Asian Social Science, 8(12), 55-66. doi: http://dx.doi.org/10.5539/ass.v8n12p55

Almasri, A. (2013). Wudzu:h Pisti@ma:1 Palmawsu:1 PalPismi: filCrabijja وجوه استعمال . الموصول الإسمي في العربية. Dirasat: Human \& Social Sciences, 40(3), 672-686. Retrieved from https://journals.ju.edu.jo/DirasatHum/

Alotaibi, A. M. (2016). Examining the learnability of English relative clauses: Evidence from Kuwaiti EFL learners. English Language Teaching, 9(2), 57-65. doi: 10.5539/elt.v9n2p57

Alotaibi, A. M., \& Alajmi, H. (2015). The acquisition of the passive alternation by Kuwaiti EFL learners. International Journal of English Linguistics, 5(1), 44-52. doi: 10.5539/ijel.v5n1p44 
Alroudhan, H. E. (2016). The acquisition of English restrictive relative clauses by Arab adult EFL learners. Advances in Language and Literary Studies, 7(1), 33-53.

Al-Washali, I. H., \& Hasnain, S. I. (2013). A comparative study on relative clause structure in English and Arabic. Language in India, 13(3), 1-21. Retrieved from http://www.languageinindia.com/

Aronin, L., \& Toubkin, L. (2002). Language interference and language learning techniques transfer in L2 and L3 immersion programmes, International Journal of Bilingual Education and Bilingualism, 5(5), 267-278. doi: $10.1080 / 13670050208667761$

Asfoor, A. (1978). An analysis of selected errors of Arabic speakers learning English (Doctoral dissertation). Retrieved from ProQuest Dissertations and Theses. (Order No. 7903018)

Bataineh, R. (2005). Jordanian undergraduate EFL students' errors in the use of the indefinite article. The Asian EFL Journal, 7(1). 56-76. Retrieved from https://www.asian-efl-journal.com/

Berzak, Y., Reichart, R., \& Katz, B. (2015). Contrastive analysis with predictive power: typology driven estimation of grammatical error distributions in ESL. Proceedings of the 19th conference on computational language learning, China, 94-102. doi: arXiv:1603.07609

Biber, D., Conrad, S., \& Leech, G. (2015). Longman student grammar of spoken and written English. Harlow, Essex: Pearson Education.

Conrad, S., \& Biber, D. (2009). Real grammar. White Plains, NY: Pearson Education. 
Cook, V. J. (1991). The poverty-of-the-stimulus argument and multicompetence. Second Language Research, 7(2), 103-117. Retrieved from http://journals.sagepub.com/home/slr/

Corder, S. P. (1967). The significance of learner's errors. IRAL-International Review of Applied Linguistics in Language Teaching, 5(1-4), 161-170. doi:10.1515/iral.1967.5.1-4.161

Crompton, P. (2011). Article errors in the English writing of advanced L1 Arabic learners: the role of transfer. The Asian EFL Journal, 50. 4-35. Retrieved from https://www.asian-efl-journal.com/doi: 10.7575/aiac.alls.v.7n.1p.33

Dulay, H. C., \& Burt, M. K. (1973). Should we teach children syntax? Language learning, 23(2), 245-258. doi: 10.1111/j.1467-1770.1973.tb00659.x

El-Yasin, M. K. (1996). The passive voice: A problem for the English-Arabic translator. Babel, 42(1), 18-26. doi: 10.1075/babel.42.1.o3ely

Hamdallah, R. W., \& Tushyeh, H. Y. (1998). A contrastive analysis of English and Arabic in relativization. Papers and Studies in Contrastive Linguistics, 34, 14152. Retrieved from https://eric.ed.gov/?id=ED271022

Hong, A. et al (2011). Collocations in Malaysian English learners' writing: A corpusbased error analysis. 3L: The Southeast Asian Journal of English Language Studies, 17, 31-44. Retrieved from https://www.ebscohost.com/discovery Jassim, Q. H. (2011). Relative clauses in Iraqi Arabic and the status of resumptive pronouns (Unpublished master's thesis). Universitat Autònoma de Barcelona, Barcelona. 
Khansir, A. A., \& Tabande, Y. (2014). The effects of Persian language on vocabulary learning of Iranian EFL students. International Journal of Language Learning and Applied Linguistics World, 6(3), 62-75. Retrieved from http://www.ijllalw.org/finalversion636.pdf

Kharma, N. (1981). Analysis of the errors committed by Arab university students in the use of English. International Review of Applied Linguistics in Language Teaching (IRAL), 19(1), pp. 333-345.

Kleinmann, H. H. (1977). Avoidance behavior in adult second language acquisition. Language learning, 27(1), 93-107. doi: 10.1111/j.1467-1770.1977.tb00294.x

Kramsch, C. (2007). Re-Reading Robert Lado, 1957, Linguistics across Cultures: Applied linguistics for language teachers. International Journal of Applied Linguistics, 17(2), 241-247. doi: https://doiorg.proxy.lib.pdx.edu/10.1111/j.1473-4192.2007.00149.x

Laks, L. (2013). Passive formation in Palestinian and Standard Arabic: Lexical vs. syntactic operations. Word Structure, 6(2), 156-180. doi: https://doi.org/10.3366/word.2013.0043

Laufer, B, \& Girsai, Nany. (2008). Form-focused instruction in second language vocabulary learning: a case for contrastive analysis and translation. Applied Linguistics, 29(4), 694-716. doi: https://doi.org/10.1093/applin/amn018

Liu, B. (2013). Effect of first language on the use of English discourse markers by L1 Chinese speakers of English. Journal of Pragmatics: An Interdisciplinary Journal of Language Studies, 45(1), 149-172. Retrieved from https://doi.org/10.1016/j.pragma.2012.11.002. 
Marckwardt, A. H. (1963). English as a second language and English as a foreign language. Publications of the Modern Language Association of America (PMLA), $78(2), 25-28$.

Myles, F. (2010). The development of theories of second language acquisition. Language Teaching, 3(03), 320-332. doi: https://doi.org/10.1017/So261444810000078

Nasser, K. (1983). Language problems of Arab students learning English as a second language in selected universities in America (Doctoral Dissertation). Retrieved from ProQuest Dissertations and Theses. (Order No. 8325830).

Noor, H. H. (1996). English Syntactic Errors by Arabic Speaking Learners: Reviewed. Retrieved from ERIC database. (ED423660)

Palmer, H. (1949). The principles of language-study. Retrieved from: https://babel.hathitrust.org/cgi/pt?id=mdp.39015005634228;view=1up;s $e q=9$

Paquot, M. (2017). L1 frequency in foreign language acquisition: recurrent word combinations in French and Spanish EFL learner writing [Special issue]. Second Language Research,33(1), 13-32. doi: 10.1177/0267658315620265

Praise, S., \& Meenakshi, K. (2014). Importance of grammar in communication. International Journal of Research Studies in Language Learning, 4(1), 97-102. doi: $10.5861 /$ ijrsll.2014.789

Qaid, Y. A., \& Ramamoorthy, L. (2011). A study of Arabic interference in Yemeni university students' English writing. Language in India, 11(4), 28-37. Retrieved from http://www.languageinindia.com/april2011/yahiaarabicinterferencefinal.pdf 
Sabbah, S. S. (2015). Negative transfer: Arabic language interference to learning English. Arab World English Journal (AWEJ), Special Issue on Translation (No. 4). Retrieved from http:/www.awej.org/

Sajaavara, K. (2000). Contrastive analysis. In Byram, M. (Ed.), Routledge encyclopedia of language teaching and learning. (pp. 205-212). London: Routledge.

Schachter, J. (1974). An error in error analysis. Language Learning, 24(2), 205-214. Retrieved from http://onlinelibrary.wiley.com.proxy.lib.pdx.edu/doi/10.1111/j.14671770.1974.tb00502.x/epdf

Schwartz, B. D., \& Sprouse, R. (1996). L2 cognitive states and the full transfer/full access model. Second Language Research, 12, 40-72. doi: $10.1177 / 026765839601200103$

Scott, M. S., \& Tucker, G. R. (1974). Error analysis and English-language strategies of Arab students. Language Learning, 24(1), 69-97. doi: 10.1111/j.14671770.1974.tb00236.x

Shalaby, A. I. A. (2014). English-and Arabic-medium of instruction and second language acquisition of English articles system by ESL Arab sophomores in Sharjah (Doctoral dissertation). The British University in Dubai (BUiD). Dubai.

Smith, B. (2001). Arabic speakers. In Ur, P. (Ed.), Learner English: A teacher's guide to interference and other problems, (pp.195-213). Cambridge: Cambridge University Press.

Sridhar, S. N. (1976). Contrastive analysis, error analysis and interlanguage: three phases of one goal. [Monograph]. Retrieved from http://eric.ed.gov. 
The Essentials of Language Teaching (2017). The National Capital Language Resource Center (NCLRC). Retrieved from http://www.nclrc.org/essentials/goalsmethods/goal.htm

Thyab, R. A. (2016). Mother-tongue interference in the acquisition if English articles by L1 Arabic students. Journal of Education and Practice, 7(3), 1-4. Retrieved from http://www.iiste.org/Journals/index.php/JEP

Touchie, H. (1983). Transfer and related strategies in the acquisition of English relative clauses by adult Arab learners (Doctoral Dissertation). Retrieved from ProQuest Dissertations and Theses. (Order No. 8319693).

Ur, P. (2006). Grammar practice activities: A practical guide for teachers. Cambridge: Cambridge University Press.

VanPatten, B., \& Williams, J. (2015). Theories in second language acquisition: An introduction. New York: Routledge.

Zhang, J. (2009). Necessity of grammar teaching. International Education Studies, 2(2), 184-187. doi: http://dx.doi.org/10.5539/ies.v2n2p184 


\section{Appendix A}

\section{Interview Questions}

The interviews will be semi-structured and all will use the following questions. Additional examples (of grammar errors and transliterations) may be used, as needed for participant understanding.

1. A) Is it easy for you to express yourself in English?

Possible prompt: What is the hardest part of writing in English?

B) Do you find yourself thinking in Arabic when writing in English?

Possible prompts: Describe your process last time you wrote a paper.

C) Do you end up with transliterated Arabic constructions? (example: \#Drink soup)

D) Do you end up with grammatical structures that are literal translations of Arabic?

$$
\text { (example: *He strong) }
$$

2. When introduced to a new grammar rule, do you compare it to Arabic grammar? Why and why not? Possible prompts: Can you give me an example?

3. Do you think it is useful to compare Arabic grammar to English grammar? Possible prompts: What have you been told about comparing grammars? 
4. Do you know you make grammatical errors that are related to the absence of equivalent structures in Arabic?

a. Absence of copula in passive voice

*The house built

b. Absence of gap in relative clauses

*This is the girl that I told you about her

*This is the house where I live in it.

c. Definite article overuse

*The globalization is changing the world.

5. What do you think are the hardest differences between Arabic grammar and English grammar?

6. Have you noticed other ways that Arabic influences your English grammar besides what I have already asked? 


\title{
Appendix B
}

\section{IRB Approval}

\author{
$\begin{array}{ll}\text { Post Office Box 751 } & 503-725-2227 \text { tel } \\ \text { Portland, Oregon 97207-0751 } & 503-725-8170 \text { fax }\end{array}$ \\ Research Integrity (Research \& Strategic Partnerships) \\ IRB (Human Subjects Research Review Committee) \\ hsmc@pdx.edu \\ Date: February 21, 2018
}

To: Susan Conrad / Aisha Alasfour, Linguistics

From: Lindsey Wilkinson, IRB Chair

\section{龟 Portland State}

Re: IRB approval for continuation of your protocol \# 174103, entitled: "Is Arabic Influencing Grammatical Errors in ESL Students? An Investigation of L1 Transfer through Error Analysis."

Approval-Expiration: February 21, 2018-March 06, 2019

\section{Notice of IRB Review and Approval - Continuing Review Expedited Review Categories 5, 6, 7; as per Title 45 CFR Part 46}

The continuation report for the project identified above has been reviewed and approved by the PSU IRB (Human Subjects Research Review Committee) and the Research Integrity office using an expedited review procedure. This is a minimal risk study. The IRB is satisfied that your provisions for protecting the rights and welfare of all subjects participating in the research are adequate. Please note the following requirements:

Approval: You are approved to conduct this research study only during the period of approval cited above, and the research must be conducted according to the plans and protocol submitted (approved copy enclosed).

Consent: You must use IRB-approved consent materials with study participants.

Changes to Protocol: Any changes in the proposed study, whether to procedures, survey instruments, consent forms or cover letters, must be outlined and submitted to the IRB immediately. The proposed changes cannot be implemented before they have been reviewed and approved by the IRB.

Continuing Review: This approval will expire on 03/06/2019. It is the investigator's responsibility to ensure a Continuing Review Report is submitted to the IRB two months before the expiration date, and that approval of the study is kept current. The Continuing Review Report is available on the Research Integrity website.

Adverse Reactions and/or Unanticipated Problems: If any adverse reactions or unanticipated problems occur as a result of this study, you are required to notify the Research Integrity office within 5 days of the event. If the issue is serious, approval may be withdrawn pending an investigation by the IRB.

Completion of Study: Please notify the $\mathbb{R B}$ as soon as your research has been completed. Study records, including protocols and signed consent forms for each participant, must be kept by the investigator in a secure location for three years following completion of the study (or per any requirements specified by the project's funding agency).

If you have questions or concerns, please contact the Research Integrity office in Research \& Strategic Partnerships at hsrrc@pdx.edu or (503) 725-2227. 